\title{
Live cell imaging with protein domains capable of recognizing phosphatidylinositol 4,5-bisphosphate; a comparative study Zsofia Szentpetery ${ }^{1}$, Andras Balla ${ }^{2}$, Yeun Ju Kim ${ }^{1}$, Mark A Lemmon ${ }^{3}$ and Tamas Balla*1
}

Address: ${ }^{1}$ Sections on Molecular Signal Transduction, Program for Developmental Neuroscience, NICHD, National Institutes of Health, Bethesda, MD 20892, USA, ${ }^{2}$ Department of Physiology, Semmelweis University, School of Medicine, Budapest, Hungary and ${ }^{3}$ Department of Biochemistry and Biophysics, School of Medicine, University of Pennsylvania, Philadelphia, PA 19104, USA

Email: Zsofia Szentpetery - szentpeteryzsofia@yahoo.com; Andras Balla - aballa@puskin.sote.hu; Yeun Ju Kim - KimYJ@mail.nih.gov; Mark A Lemmon - mlemmon@mail.med.upenn.edu; Tamas Balla* - ballat@mail.nih.gov

* Corresponding author

Published: 21 September 2009

BMC Cell Biology 2009, 10:67 doi:10.1/86/147|-2121-10-67
Received: 28 April 2009

Accepted: 21 September 2009

This article is available from: http://www.biomedcentral.com/147I-2/21//0/67

(c) 2009 Szentpetery et al; licensee BioMed Central Ltd.

This is an Open Access article distributed under the terms of the Creative Commons Attribution License (http://creativecommons.org/licenses/by/2.0), which permits unrestricted use, distribution, and reproduction in any medium, provided the original work is properly cited.

\begin{abstract}
Background: Phosphatidylinositol 4,5-bisphosphate $\left[\operatorname{Ptdlns}(4,5) P_{2}\right]$ is a critically important regulatory phospholipid found in the plasma membrane of all eukaryotic cells. In addition to being a precursor of important second messengers, $\operatorname{Ptdlns}(4,5) P_{2}$ also regulates ion channels and transporters and serves the endocytic machinery by recruiting clathrin adaptor proteins. Visualization of the localization and dynamic changes in $\operatorname{Ptdlns}(4,5) P_{2}$ levels in living cells is critical to understanding the biology of $\operatorname{Ptdlns}(4,5) P_{2}$. This has been mostly achieved with the use of the pleckstrin homology (PH) domain of PLC $\delta$ I fused to GFP. Here we report on a comparative analysis of several recently-described yeast $\mathrm{PH}$ domains as well as the mammalian Tubby domain to evaluate their usefulness as $\operatorname{Ptdlns}(4,5) P_{2}$ imaging tools.

Results: All of the yeast $\mathrm{PH}$ domains that have been previously shown to bind $\operatorname{Ptdlns}(4,5) P_{2}$ showed plasma membrane localization but only a subset responded to manipulations of plasma membrane Ptdlns $(4,5) P_{2}$. None of these domains showed any advantage over the PLC $\delta$ IPH-GFP reporter and were compromised either in their expression levels, nuclear localization or by causing peculiar membrane structures. In contrast, the Tubby domain showed high membrane localization consistent with $\operatorname{Ptdlns}(4,5) P_{2}$ binding and displayed no affinity for the soluble headgroup, Ins $(I, 4,5) P_{3}$. Detailed comparison of the Tubby and PLC $\delta I P H$ domains showed that the Tubby domain has a higher affinity for membrane $\operatorname{Ptdlns}(4,5) P_{2}$ and therefore displays a lower sensitivity to report on changes of this lipid during phospholipase $C$ activation.

Conclusion: These results showed that both the PLC $\delta$ IPH-GFP and the GFP-Tubby domain are useful reporters of $\operatorname{Ptdlns}(4,5) P_{2}$ changes in the plasma membrane, with distinct advantages and disadvantages. While the PLC $\delta$ IPH-GFP is a more sensitive reporter, its $\operatorname{Ins}(I, 4,5) \mathrm{P}_{3}$ binding may compromise its accuracy to measure Ptdlns $(4,5) P_{2}$ changes. The Tubby domain is more accurate to report on $\operatorname{Ptdlns}(4,5) P_{2}$ but its higher affinity and lower sensitivity may limit its utility when phospholipase $\mathrm{C}$ activation is only moderate. These studies also demonstrated that similar changes in $\operatorname{Ptdlns}(4,5) P_{2}$ levels in the plasma membrane can differentially regulate multiple effectors if they display different affinities to $\operatorname{Ptdlns}(4,5) P_{2}$.
\end{abstract}




\section{Background}

Phosphatidylinositol 4,5-bisphosphate $\left[\operatorname{Ptd} \operatorname{Ins}(4,5) P_{2}\right]$ is the major polyphosphoinositide species found in the plasma membrane (PM) of all eukaryotic cells. This regulatory lipid has several functions in the PM: first, it was identified as the primary substrate of receptor-mediated phospholipase C (PLC) activation, to yield the second messengers, inositol-1,4,5-trisphosphate ( $\left.\mathrm{InsP}_{3}\right)$ and diacylglycerol [1]. PtdIns $(4,5) P_{2}$ is also important for endocytosis of PM proteins through its binding to several clathrin adaptors [2]. Moreover, $\operatorname{PtdIns}(4,5) P_{2}$ is required for the proper functioning of many ion channels and transporters $[3,4]$ and also contributes to the regulation of actin polymerization [5] and attachment of the PM to the actin cytoskeleton [6]. Although the majority of $\operatorname{PtdIns}(4,5) \mathrm{P}_{2}$ is found in the PM, functional data suggest that the lipid may also regulate signaling complexes in other membranes and even within the nucleus [7]. The pivotal importance and pleiotropic functions of PtdIns $(4,5) P_{2}$ have demanded that its distribution and dynamics be followed with subcellular resolution preferentially in living cells. This was finally achieved with the introduction of the PLC $\delta 1$-PH-domain GFP chimera as a molecular probe to detect PtdIns $(4,5) P_{2}$ in eukaryotic cells $[8,9]$.

The PLC81PH-GFP reporter has since been widely used successfully to monitor PtdIns $(4,5) P_{2}$ dynamics under a variety of cellular settings [10]. This reporter has not shown significant amounts of PtdIns $(4,5) \mathrm{P}_{2}$ in intracellular membranes other than endocytic vesicles in live cells [11], although it detected some of the lipid in internal membranes in an EM application [12]. This could reflect low abundance of PtdIns $(4,5) \mathrm{P}_{2}$ in internal membranes or a requirement for other components present only in the PM for the PtdIns $(4,5) \mathrm{P}_{2}$-dependent membrane recruitment of the PLC 1 PH-GFP probe. Moreover, because of its high-affinity binding to Ins $\mathrm{P}_{3}$, the interpretation of the data obtained by the use of the PLC $\delta_{1} \mathrm{PH}$ domain has become highly debated [10]. Several studies have shown that $\mathrm{InsP}_{3}$ can displace the PLC 1 PH-GFP reporter from the membrane without an apparent change in the level of PtdIns $(4,5) P_{2}[13,14]$. Although, $\operatorname{InsP}_{3}$ is mostly formed from $\operatorname{PtdIns}(4,5) P_{2}$, if the affinity of the probe is significantly higher for the soluble InsP $_{3}$ than for the membrane-bound PtdIns $(4,5) P_{2}$, the translocation of the probe from the membrane to the cytosol will be disproportionally higher than the actual lipid decrease in the membrane [13].

Research in the last 10 years has clearly demonstrated that phosphoinositides may not be the sole determinants of the cellular distribution of phosphoinositide-binding protein-modules [15]. This raises the possibility that functionally distinct inositide pools are differentially reported on by different protein modules even if they recognize the same phosphoinositide species. Because of these new developments and the limitations of the PLC81PH-GFP, there is a need to evaluate other potential PtdIns $(4,5) P_{2}$ binding PH domains as reporters of the lipid in a true cellular setting. Several protein modules have been shown to recognize PtdIns $(4,5) \mathrm{P}_{2}$ based on in vitro binding assays. Moreover, a detailed analysis of the PH domains identified in Saccharomyces cerevisiae also revealed that many PH domains showing relatively limited phosphoinositide binding specificities could detect specific lipid pools probably because of their interaction with other components of signaling domains where these lipids are formed. Therefore, even some of the domains that lack in vitro lipid binding specificity might be useful in reporting on some specific signaling inositol lipid pools within the cells. However, to decide whether a reporter is indeed a good sensor of PtdIns $(4,5) P_{2}$ one has to investigate the properties of these domains in live cells with controlled manipulation of $\operatorname{Ptd} \operatorname{Ins}(4,5) P_{2}$.

In the present study we evaluated several yeast PHdomains characterized in [16] as well as the Tubby domain of the mammalian Tubby protein [17] for their ability to follow PtdIns $(4,5) \mathrm{P}_{2}$ changes in mammalian cells. Our analysis shows that many but not all of the examined yeast $\mathrm{PH}$ domains can follow PtdIns $(4,5) \mathrm{P}_{2}$ changes, but all have limitations and none is remotely better than the PLC81PH domain. A more detailed comparison with the Tubby domain shows that while the latter is a good PtdIns $(4,5) \mathrm{P}_{2}$ reporter, its high affinity to the lipid and slow dissociation can also pose problems leading to underestimation of the PtdIns $(4,5) \mathrm{P}_{2}$ changes. The similarities yet profound differences in the behavior of these isolated PtdIns $(4,5) \mathrm{P}_{2}$ domains is a perfect example of how PtdIns $(4,5) \mathrm{P}_{2}$ can interact and regulate multiple effector proteins simultaneously and yet differentially.

\section{Results \\ Localization responses of lipid binding domains during manipulation of PM Ptdln(4,5) $P_{2}$}

Several yeast PH domains showed PM localization in spite of varying in vitro inositide binding specificity as described in [16]. A selected panel of these PH domains was tested for their abilities to respond to changes in PM PtdIns $(4,5) \mathrm{P}_{2}$ levels. In addition, the Tubby domain of the Tubby protein [18], which has been described as a specific PtdIns $(4,5) \mathrm{P}_{2}$ reporter [19], was analyzed in more detail in comparison to the widely used PLC81PH-GFP probe. The purpose of these studies was to evaluate the features of these protein domains in a cell line in which the phosphoinositide changes have been well characterized in the same laboratory. Two detailed analysis with similar goals have been recently published, one using the full-length 
Tubby protein [20] and the other characterizing a mutant form of the isolated Tubby domain [21].

Table 1. lists the PH domains tested in this study. The probes were expressed in HEK293-AT1 cells, a cell line stably expressing the rat $\mathrm{AT}_{1 \mathrm{a}}$ angiotensin receptor, and in which stimulation with $100 \mathrm{nM}$ AngII causes a robust PLC activation with complete translocation of the PLC $81-\mathrm{PH}-$ GFP and a $\sim 80 \%$ decrease of the ${ }^{32} \mathrm{P}$ - or $\left[{ }^{3} \mathrm{H}\right]$-inositollabeled PtdIns $(4,5) \mathrm{P}_{2}$ pools within 30 second stimulation [22]. The recently described rapamycin-inducible 5-phosphatase recruitment system was used to eliminate PtdIns $(4,5) \mathrm{P}_{2}$ without PLC activation [23]. As shown in Table 1, all of these PH domains showed PM localization in agreement with previous reports [16]. Importantly, none of the domains showed any intracellular localization (apart from nuclear enrichment, see below). Several of the domains lacked a response to $\operatorname{PtdIns}(4,5) \mathrm{P}_{2}$ decrease either evoked by AngII stimulation or by 5-ptase recruitment. These included the $\mathrm{PH}$ domains of Cla4, Skm1, and Slm2 (see additional file 1). The other domains, namely: Num1-PH, Slm1-PH and Opy1-PH, displayed a transient, and incomplete translocation from the membrane to the cytosol upon AngII stimulation and except for SIm1p, these domains completely lost their membrane localization in response to the 5-ptase recruitment to the PM (Fig. 1). In case of Slm1-PH the translocation to the cytosol after phosphatase recruitment was partial indicating that the probe still binds to PtdIns $4 P$ generated by the 5-ptase. Indeed, the addition of $10 \mu \mathrm{M}$ wortmannin completely eliminated the remaining localization of the Slm1-PH domain (not shown).

There were several other issues that made some of these domains less than optimal. The Num1-PH domain - which has the highest specificity of PtdIns $(4,5) \mathrm{P}_{2}$ binding in vitro [16], - showed very poor expression when fused to the C-terminus of GFP. When the PH domain was placed in front of the GFP, its expression has significantly improved, but many cells expressing the domain showed peculiar structures with intense fluorescence. These appeared as vesicles that had just bud off but are still attached to the outer surface of the PM (see additional file 1). The Opy1 PH domain, on the other hand, showed very high affinity to the nucleus and nucleolus. This was partially overcome by placing a nuclear export signal in front of the GFP fusion protein (see additional file 1). These results collectively indicated that the lipid binding characteristics of the yeast PH domains are not identical and in some cases the membrane localization is likely influenced by factors other than phosphoinositides. Having tested the yeast PH domains, we decided to subject the mammalian Tubby domain for a more detailed comparison with the widely used PLC $\delta 1$ PH-GFP.

\section{Comparative analysis of the Tubby-domain and the PLC $\delta$ I-PH domain}

I. The Tubby domain binds to the PM with higher affinity

When expressed in HEK293-AT1 cells, a significantly higher fraction of PLC81-PH was found cytosolic compared to the Tubby-domain. Fig 2A shows representative images of HEK-293-AT1 cells expressing the two reporters either individually or together, tagged with fluorescent proteins of different colors (Tubby-domain-GFP and PLC81-PH-mRFP). To quantify these differences, fluorescent intensity values were recorded along line-intensity histograms taken over the cells (Fig. 2B) and the PM vs. cytoplasmic intensity ratios were calculated. This ratio was substantially higher $(6.9 \pm 1.23)$ for the Tubby-domain than for PLC81PH-GFP $(2.1 \pm 0.33$, means \pm S.E.M, $\mathrm{n}=$

Table I: Localization responses of selected yeast PH domains and the human Tubby domain expressed in HEK293-ATI or COS-7 cells.

\begin{tabular}{|c|c|c|c|c|}
\hline PH domain & $\begin{array}{l}\text { Subcellular } \\
\text { Localization }\end{array}$ & $\begin{array}{l}\text { Response to } \\
\text { Angll stimulation }\end{array}$ & $\begin{array}{l}\text { Response to } \\
\text { PtdIns }(4,5) P_{2} \\
\text { elimination by } \\
\text { 5-ptase }\end{array}$ & $\begin{array}{l}\text { Presumptive inositide } \\
\text { dependence of } \\
\text { PM localization }\end{array}$ \\
\hline PLC $\delta I-P H$ & PM & $\begin{array}{l}\text { transient } \\
\text { translocation }\end{array}$ & $\begin{array}{l}\text { complete } \\
\text { translocation }\end{array}$ & $\operatorname{Ptdlns}(4,5) \mathrm{P}_{2}$ \\
\hline Cla4p-PH & PM & no change & no change & inositide independent \\
\hline Numlp-PH & PM & $\begin{array}{l}\text { transient } \\
\text { translocation }\end{array}$ & $\begin{array}{l}\text { complete } \\
\text { translocation }\end{array}$ & $\operatorname{Ptdlns}(4,5) \mathrm{P}_{2}$ \\
\hline Skm Ip-PH & PM & no change & no change & inositide independent \\
\hline Opylp-PH & PM & $\begin{array}{l}\text { transient } \\
\text { translocation }\end{array}$ & $\begin{array}{l}\text { complete } \\
\text { translocation }\end{array}$ & $\operatorname{Ptdlns}(4,5) \mathrm{P}_{2}$ \\
\hline $\begin{array}{l}\text { Yill } 05 c / \\
\text { SIm Ip-PH }\end{array}$ & PM & $\begin{array}{l}\text { transient } \\
\text { translocation }\end{array}$ & $\begin{array}{l}\text { partial } \\
\text { translocation }\end{array}$ & $\begin{array}{l}\text { Ptdlns }(4,5) P_{2} \\
\text { Ptdlns } 4 P\end{array}$ \\
\hline $\begin{array}{l}\text { Yn1047/ } \\
\text { Slm2p-PH }\end{array}$ & PM & no change & no change & inositide independent \\
\hline Tubby domain & PM & $\begin{array}{l}\text { transient } \\
\text { translocation }\end{array}$ & $\begin{array}{l}\text { complete } \\
\text { translocation }\end{array}$ & $\operatorname{Ptdlns}(4,5) P_{2}$ \\
\hline
\end{tabular}


A

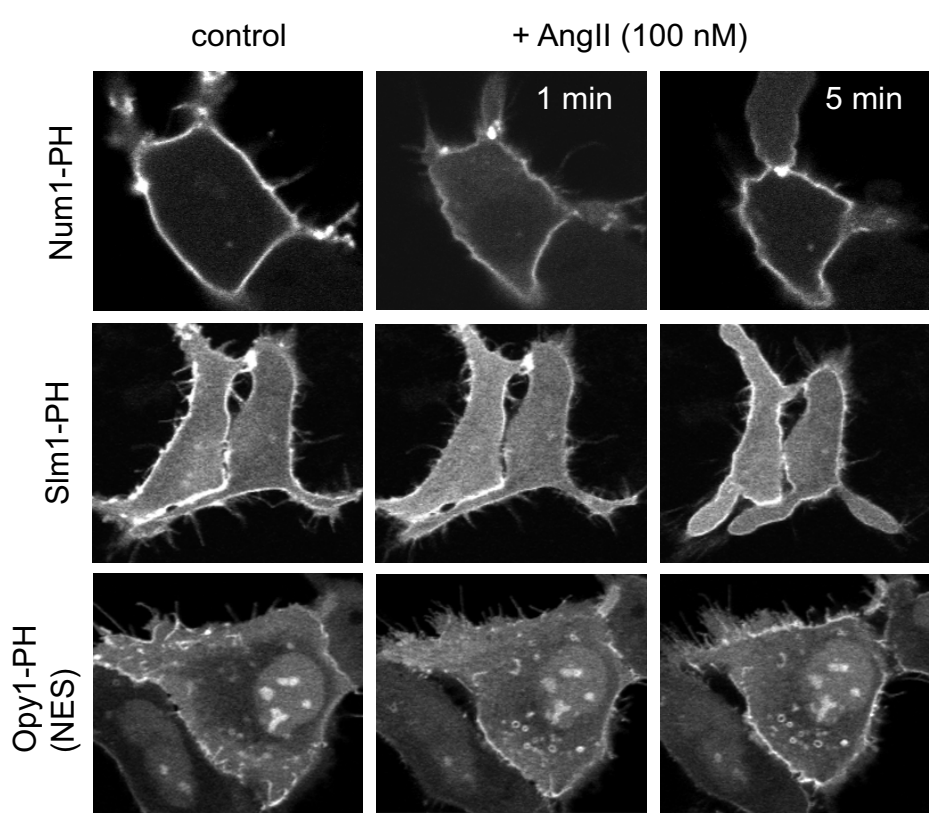

B
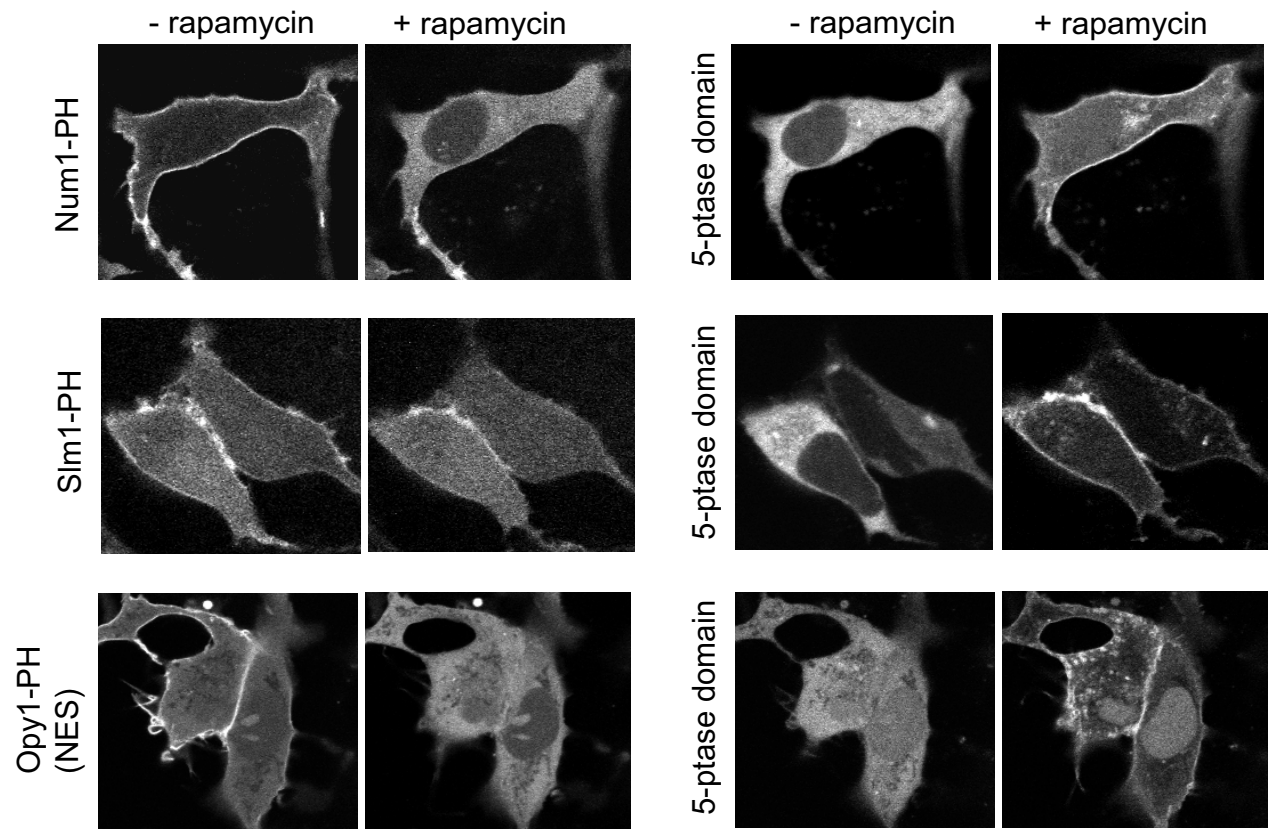

Figure I

Translocation responses of selected PH domains after PLC activation or phosphoinositide 5-phosphatase action. The GFP-tagged versions of the indicated PH domains were expressed either in HEK293-ATI cells for Angll (I00 nM) stimulation (panel A) or in COS-7 cells for 5-phosphatase action (panel B). Angll stimulation causes rapid PLC activation with a substantial decrease in Ptdlns(4,5) $\mathrm{P}_{2}$ levels ( $80 \%$ [22] but these selected probes showed only a small and transient translocation response from the membrane to the cytosol. For 5-phosphatase recruitment, COS-7 cells were transfected with a PM-targeted FRB-CFP and a mRFP-FKBP-I2-5-phosphatse domain along with the GFP-tagged PH domain. Rapamycin (I00 nM) addition rapidly recruits the 5-phosphatase to the $\mathrm{PM}\left(\mathrm{B}\right.$ panel, right) and eliminates $\mathrm{Ptdlns}(4,5) \mathrm{P}_{2}[23]$. Some of the $\mathrm{PH}$ domains completely lose localization (Num I or Opyl) while others (such as SIm I) shows only a partial translocation. See Table I for a complete list of the responses found with the other $\mathrm{PH}$ domains. 

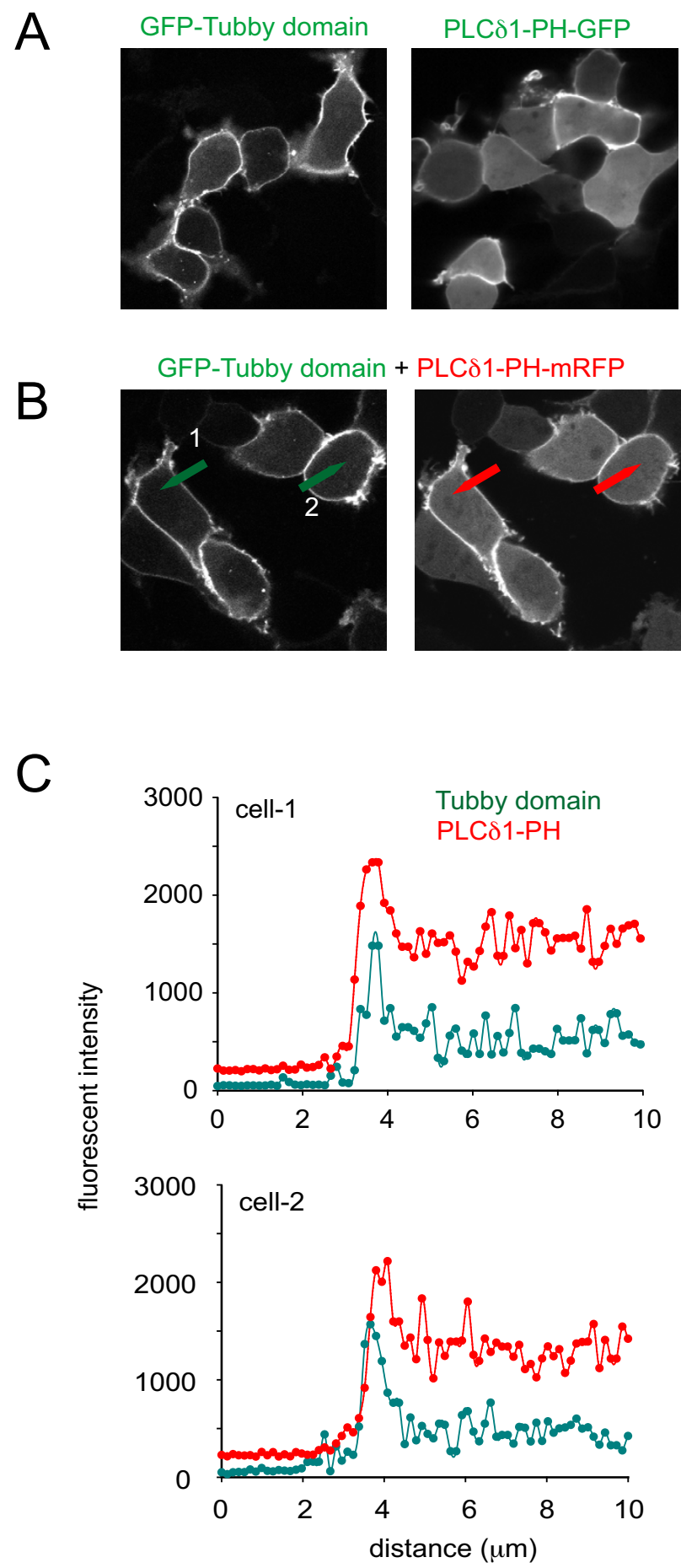

\section{Figure 2}

Cellular distribution of the Tubby-domain and PLC $\delta$ IPH domain expressed in HEK293-AT I cells. The GFPTubby-domain and PLC $\delta$ IPH-GFP were expressed either separately (panel A) or were co-expressed (here the PLCdIPH was tagged with mRFP, panel B) in HEK293-ATI cells. Confocal images show a stronger localization of the Tubby domain to the PM. The PM vs. cytoplasmic fluorescent ratios were calculated from line intensity histograms taken across representative sections of the cells (shown by arrows in the Figures on Panel B). Representative intensity histograms are shown in Panel C from cells $I$ and 2 as shown in Panel B. The background fluorescence was subtracted from both the average PM and cytoplasmic fluorescence values when calculating the $\mathrm{F}_{\mathrm{PM}} / \mathrm{F}_{\text {cyto }}$ ratios. These values are found in the text. 
25). This observation already indicated that the two probes have different apparent affinities to the PM, presumably to PtdIns $(4,5) \mathrm{P}_{2}$. Based on these results, one would expect to see a competition between the two domains for the plasma membrane PtdIns $(4,5) \mathrm{P}_{2}$ pools. However, no competition was observed between the two probes. This was consistent with our finding that the cytosol to PM ratio of either probe did not show significant differences depending on the expression level (data not shown). These results suggested that cells can dynamically up-regulate their PtdIns $(4,5) \mathrm{P}_{2}$ pools when such reporters are expressed and keep a fraction of the lipids sequestered. This could explain the lack of saturation of membrane binding of the domains.

To further elucidate the difference in the membrane binding properties, namely, the association/dissociation rates and mobility of the two probes, we performed fluorescence recovery after photobleaching (FRAP) analysis in HEK293-AT 1 cells expressing the GFP-tagged versions of the respective reporters. Selected areas of the PM were bleached and the recovery of fluorescence was recorded (see additional file 3 and 4 ). The mobile fraction- and $\mathrm{T}_{1 /}$ ${ }_{2}$ values were calculated as described in the Materials and Methods. There was a small but statistically significant difference between the mobile fraction values of Tubby-GFP $(73.8 \pm 2.33$, S.E.M., $\mathrm{n}=90)$ and $\mathrm{PLC} \delta_{1}$ PH-GFP $(79.8 \pm$ 2.67, S.E.M., $\mathrm{n}=90$, expressed as $\%$ of prebleach values). $(p<0.05)$. In contrast, the $T_{1 / 2}$ values showed more then a two fold difference between the two reporters [3.1 \pm 0.33 $\sec ($ S.E.M., $\mathrm{n}=90$ ) and $1.2 \pm 0.09 \mathrm{sec}$ (S.E.M., $\mathrm{n}=90$ ) for the Tubby-GFP and PLC $\delta_{1}$ PH-GFP, respectively]. This difference was highly significant $(\mathrm{p}<0.0001)$. In fact, the $\mathrm{T}_{1 /}$ ${ }_{2}$ value of the Tubby domain was close to that measured previously for the membrane anchored GFP-CAAX domain [24] (the $\mathrm{T}_{1 / 2}$ value for PLC81PH-GFP in that study was found identical to our current measurement). These results were consistent with a higher affinity of the Tubby-domain-GFP probe to its PM binding partner, most likely reflecting its slower dissociation rate. It is important to note that in a FRAP analysis the recovery of the fluorescence in the bleached area can occur as a result of both lateral diffusion (starting from the borders of the bleached area) and dissociation from the membrane to the cytosol and rapid re-association (which should not differ regardless of the site within the bleached area). This feature was elegantly utilized to determine the diffusion properties of several GFP-fused PH domains in a recent study [25]. In the present analysis we selected the central area within a larger bleached region (additional file 2) to minimize the effects of lateral diffusion. Yet, the slower recovery of the Tubby domain was consistent with a rate similar to that of simple lateral diffusion.

\section{Response to agonist-induced PLC activation}

Initial experiments showed that while PLC 1 PH-GFP showed a full translocation in $>90 \%$ of cells from the membrane to the cytosol after $100 \mathrm{nM}$ AngII stimulation, the Tubby domain-GFP construct had much more variable responses ranging from no detectable change to a full translocation. For a better comparison of the two probes during PLC activation, the GFP-tagged Tubby-domain and the mRFP-tagged PLC81-PH domain were co-expressed in HEK293-AT1 cells. The dynamics of the redistribution of the two probes during this process was then followed after stimulation with different concentrations of AngII. At high concentrations of AngII (0.1-1 $\mu \mathrm{M})$ both reporters translocated rapidly from the membrane to the cytosol. However, while the translocation of PLC81PH-GFP was almost always complete, that of the Tubby domain was often partial. When the AngII concentration was lowered to $30 \mathrm{nM}$, there was a significantly longer delay in the translocation of the Tubby-domain compared to that of the PLC81-PH domain (Fig. 3, Panel A). Moreover, while a complete translocation of PLC $\delta 1$ PH-GFP always occurred at this concentration of AngII stimulation, the Tubby-domain either failed to translocate or did it only partially or with a significant time delay. As shown in Fig. $3 \mathrm{~B}$, the average time required for half maximal translocation of PLC 1 PH $-m R F P$ was $3.8 \pm 0.3 \mathrm{sec}$, while that of the Tubby-domain was $6.7 \pm 0.3 \mathrm{sec}$ (Means \pm S.E.M, $\mathrm{n}=54$ ) $(\mathrm{p}<0.001)$.

To determine the extent of maximum translocation of the reporters, high concentration of ionomycin $(10 \mu \mathrm{M})$ was added after AngII stimulation. The high $\mathrm{Ca}^{2+}$ concentration attained with this amount of ionomycin activates endogenous PLC enzymes even without G-protein activation, completely eliminating both $\operatorname{PtdIns}(4,5) P_{2}$ and PtdIns4P from the cells $[9,26]$. This ensures displacement of all expressed reporters from the membrane allowing us to determine the fraction of the probe that showed translocation during agonist stimulation. As with the agonist, a significant delay in the translocation of the Tubbydomain $\left(\mathrm{T}_{1 / 2}=27.2 \pm 2.62 \mathrm{sec}, \mathrm{n}=54\right)$ compared to that of the PLC 11 PH-GFP (half $\max 14.0 \pm 1.54 \mathrm{sec}, \mathrm{n}=54$ ) (p $<0.001$ ) was observed upon ionomycin addition (Fig. 3B). Moreover, in the case of the PLC 1 PH-GFP the cytoplasmic fluorescent intensity increases after AngII and ionomycin were comparable ( $92 \%$ vs $100 \%$ ), whereas in the case of the Tubby-domain-GFP, the intensity increase after AngII was only $30 \%$ of that observed after ionomycin. This confirmed the observation that $30 \mathrm{nM}$ AngII did not displace the Tubby-domain completely from the PM. It is worth noting that lower concentration of ionomycin $(1 \mu \mathrm{M})$ that releases $\mathrm{Ca}^{2+}$ and induces capacitative $\mathrm{Ca}^{2+}$ entry evoked only a small or no response in cases of either reporter in naïve cells in agreement with other reports [21]. 

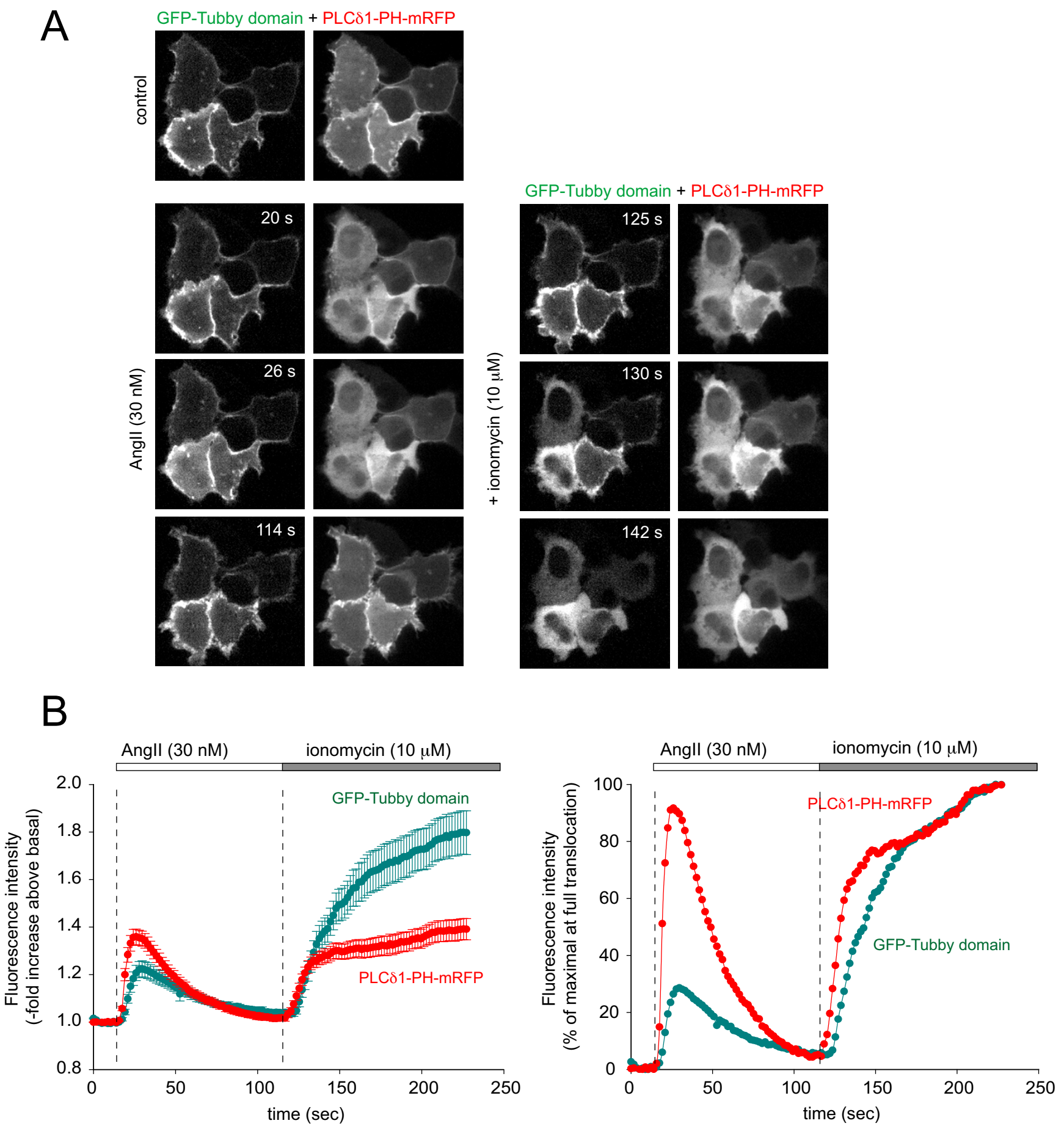

Figure 3

Translocation responses of Tubby-domain and PLC $\delta$ IPH domain in AngII and ionomycin stimulated HEK293ATI cells. HEK293-ATI cells were co-transfected with the GFP-Tubby-domain and the PLC $\delta$ IPH-mRFP constructs. After 24 $\mathrm{h}$, cells were analyzed by confocal microscopy. Cells were stimulated with $30 \mathrm{nM}$ Angll (at $16 \mathrm{~s}$ ) followed by $10 \mu \mathrm{M}$ ionomycin (at II7 s) as indicated. Panel A shows a representative image series recorded at the indicated time points. Panel B shows the average responses (cytoplasmic fluorescence increase) of 50-54 cells (mean \pm S.E.M) (left) and the average curve normalized to the maximal cytoplasmic fluorescence attained after ionomycin treatment (full translocation) (Panel B, right). Note the significantly slower and only partial response of the Tubby domain after Angll stimulation. 
In a subsequent set of experiments, we examined the response of the reporters to overexpresssion of a constitutively active $\mathrm{Gq}\left(\mathrm{Gq}^{*}\right)$. Gq mediated PLC activation has been the proposed mechanism by which the transcription factor Tubby is released from the PM allowing its diffusion into the nucleus [18]. As in the previous experiments, the two reporters tagged with different color fluorescent proteins were co-expressed with the constitutively active $\alpha$ subunit of $\mathrm{Gq}^{*}$. In a large number of cells, the decrease of PtdIns $(4,5) \mathrm{P}_{2}$ due to PLC $\beta$ activation was apparent, shown by a full or partial translocation of the PLC $\delta 1 \mathrm{PH}-$ GFP. The PM vs. cytoplasm ratio of the probe was $1.0 \pm$ 0.10 in a selected panel of cells, which is essentially a full translocation. However, in the very same cells, the Tubbydomain was only partially translocated to the cytosol. The PM vs cytoplasm ratio was reduced to $2.3 \pm 0.21$ from its control levels ( $6.9 \pm 1.23)$. Fig. 4, Panel A shows representative images: one, where the Tubby-domain localization is clearly visible, while the PLC81PH domain is completely cytosolic (Panel A, upper images), and another, where both reporters are cytosolic (Panel A, lower images). Importantly, even a low concentration of AngII (10 $\mathrm{nM}$ ) rapidly displaced the remaining Tubby-domain from the PM indicating that $\mathrm{Gq}^{*}$ has sensitized the system for a Gq-coupled receptor agonist (Fig. 4, Panel B).

\section{Response to Ptdlns $(4,5) P_{2}$ dephosphorylation}

Next, we studied the translocation of the probes when PtdIns $(4,5) \mathrm{P}_{2}$ was eliminated with the help of a polyphosphoinositide 5-phosphatase (5-ptase). For this, we used the rapamycin-induced recruitment of the type IV 5-ptase to the PM that can acutely eliminate $\operatorname{PtdIns}(4,5) \mathrm{P}_{2}[23]$ in COS-7 cells. We chose COS-7 cells because expression of the four constructs required for these studies did not yield high enough levels in HEK293 cells to see a robust 5phosphatase response. Cells were transfected with the PM targeted FRB-CFP, the 5-ptase-domain fused to FKBP12cerulean, Tubby-domain-GFP and PLC $\delta 1 P H-m R F P$. Addition of $100 \mathrm{nM}$ rapamycin causes rapid heterodimerization of the membrane-anchored FRB with the FKBP12 protein fused to the cytosolic 5-ptase domain causing rapid translocation of the 5-ptase domain to the PM. (In this transfection regime the translocation of the enzyme cannot be followed as both proteins are tagged with a version of the CFP to keep the other colors for the Tubby domain and PLC 1 PH domain). Rapamycin led to the prompt and complete loss of both the Tubby-domain and PLC81PH domain PM localization (Fig. 5A). Unlike with agonist or ionomycin stimulation, there was no significant difference between the speed and extent of translocation of the two reporters (Fig. 5B). The half maximal translocation of Tubby-domain occurred at $10.9 \pm 2.8 \mathrm{sec}$ and for the PLC $1 \mathrm{PH}$ domain this was $10.4 \pm 3.1$, respectively $(n=10)$ (N.S. difference).

\section{Ins $(I, 4,5) P_{3}$ and $P t d I n s(4,5) P_{2}$ binding properties of the Tubby domain}

Previous reports have suggested that the Tubby domain does not bind Ins $\mathrm{P}_{3}$ although no direct binding data have been presented [18]. To compare the inositol phosphate and inositol lipid binding characteristics of these reporters, we created the Tubby-domain-GFP fusion protein for bacterial expression in a similar manner as described for the PLC 1 PH-GFP [27]. First, the binding of $\left[{ }^{3} \mathrm{H}\right]$ Ins $(1,4,5) \mathrm{P}_{3}$ to the two recombinant proteins was examined under identical conditions. As shown in Fig. 6, Panel A, PLC $\delta 1$ PH-GFP showed significant Ins $\mathrm{P}_{3}$ binding that was displaced by increasing amounts of the unlabeled ligand (as described in [27]). In contrast, very little (if any) $\left[{ }^{3} \mathrm{H}\right]-\operatorname{Ins}(1,4,5) \mathrm{P}_{3}$ binding was found to the Tubbydomain-GFP protein. However, binding of Tubbydomain-GFP and PLC 1 PH-GFP to lipid vesicles containing PtdIns $(4,5) \mathrm{P}_{2}$ was very similar suggesting that the lack of InsP $\mathrm{P}_{3}$ binding was not due to misfolding of the Tubbydomain. However, while the PLC $1 \mathrm{PH}$ domain could be displaced from the PtdIns $(4,5) \mathrm{P}_{2}$ containing vesicles by increasing concentrations of $\mathrm{InsP}_{3}$, the Tubby-domain showed no such displacement with InsP $_{3}$ (Panel B). These experiments showed that Tubby-domain indeed shows no significant InsP $\mathrm{P}_{3}$ binding.

\section{Inhibitory effects of the PLC $\delta I P H-G F P$ and Tubby- domain-GFP on $\mathrm{Ca}^{2+}$ signaling}

Expression of protein domains that bind to $\operatorname{PtdIns}(4,5) \mathrm{P}_{2}$ and/or InsP $\mathrm{P}_{3}$ can exert an inhibitory effect on $\mathrm{Ca}^{2+}$ signaling. Binding to PtdIns $(4,5) \mathrm{P}_{2}$ can sequester a fraction of the lipid in the membrane and also hamper its availability to PLC enzymes. Binding and buffering of $\operatorname{InsP}_{3}$, on the other hand, will delay the onset of the $\mathrm{Ca}^{2+}$ release and also inhibit coupling between the individual $\mathrm{Ca}^{2+}$ release events causing a slower and smaller cytoplasmic $\mathrm{Ca}^{2+}$ increase $[28,29]$. We, therefore, compared the effects of overexpression of the Tubby-domain-mRFP (a pure PtdIns $(4,5) \mathrm{P}_{2}$ binder), PLC $1 \mathrm{PH}-\mathrm{mRFP}$ (a mixed PtdIns $(4,5) \mathrm{P}_{2}$ and Ins $\mathrm{P}_{3}$ binder) and the p130PH-mRFP (a clear Ins $\mathrm{P}_{3}$ binder with similar affinity to that of the PLC81PH domain [28]) on the agonist-induced $\mathrm{Ca}^{2+}$ signals. Red versions of these constructs were used not to interfere with the $\mathrm{Ca}^{2+}$ measurements with Fura-2. At the end of the experiments high concentration of ionomycin $(10 \mu \mathrm{M})$ was used to release the constructs to the cytosol so that their red fluorescence intensities within the individual cells could be comparably determined as a quantitative measure of their expression level. COS-7 cells stimulated via their endogenous $\mathrm{P}_{2 \mathrm{Y}}$ receptor were used in these studies because ATP causes modest PLC activation and $\mathrm{InsP}_{3}$ increases, where interference from the expressed constructs could be better assessed than in the HEK293$\mathrm{AT}_{1}$ cells, where the robust PLC activation can override the inhibitory effects of these molecules. 
A

\section{GFP-Tubby domain + PLC $\delta 1-P H-m R F P+$ Gq $^{*}$}
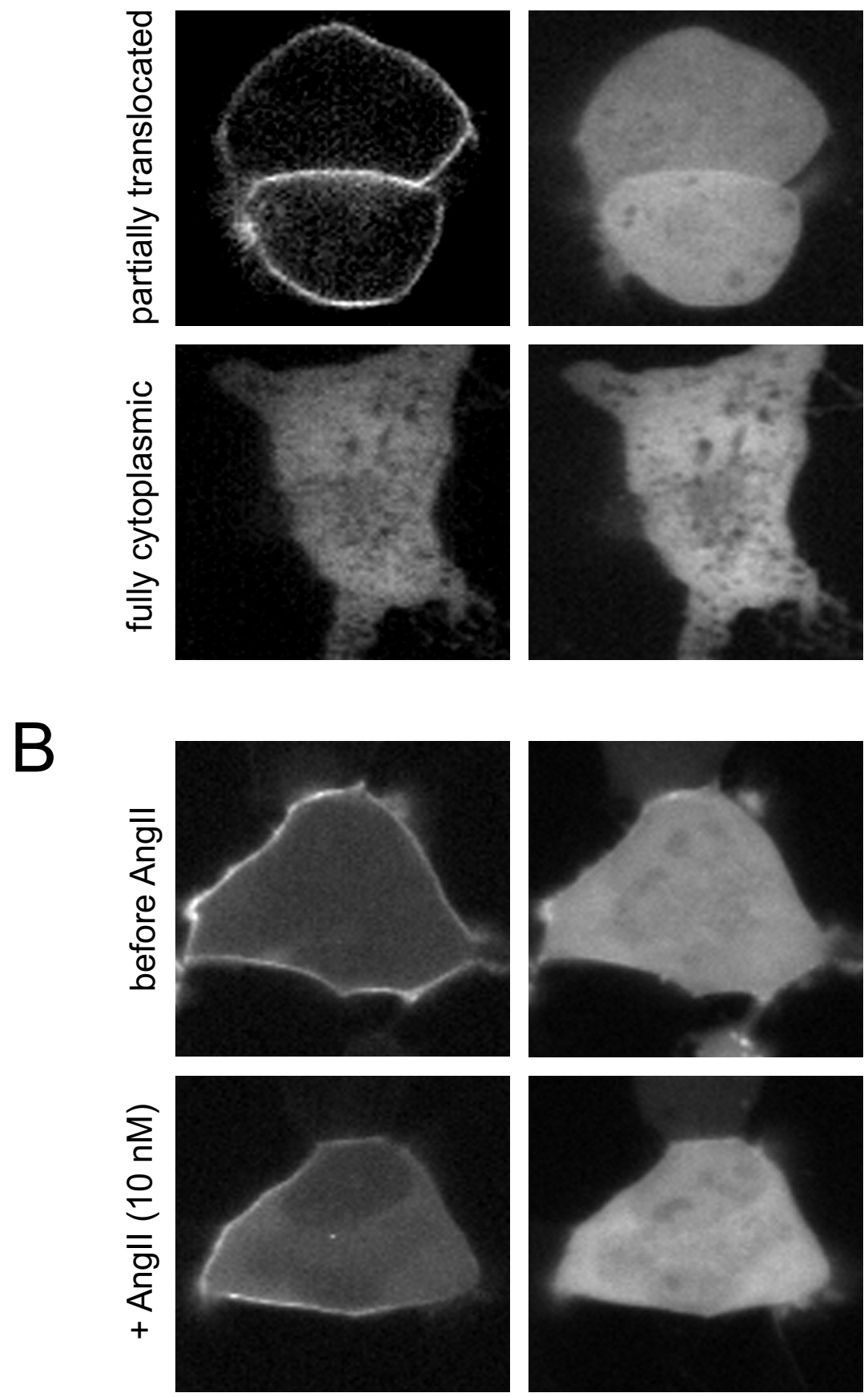

Figure 4

Distribution of the Tubby-domain and PLC $\delta$ IPH domain in cells expressing a constitutively active Gq protein. HEK293-ATI cells were co-transfected with the GFP-Tubby-domain, PLC $\delta$ I-PH-GFP plasmids together with a constitutively active $\mathrm{Gq} \alpha$-subunit (Q209L). Panel A shows cells in which the PLC $\delta$ I-PH localization is completely lost while that of the Tubby domain is still quite substantial (upper) while in some cells both construct completely lose membrane localization (lower). Panel B shows an example where a cell that still shows substantial localization of the Tubby domain loses its PM localization after stimulation with even a low concentration (I0 nM) of Angll. 
A

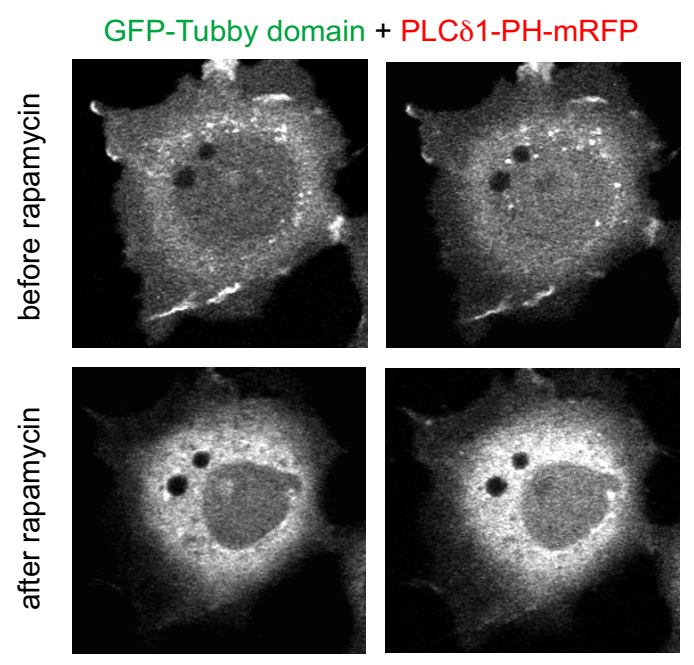

B
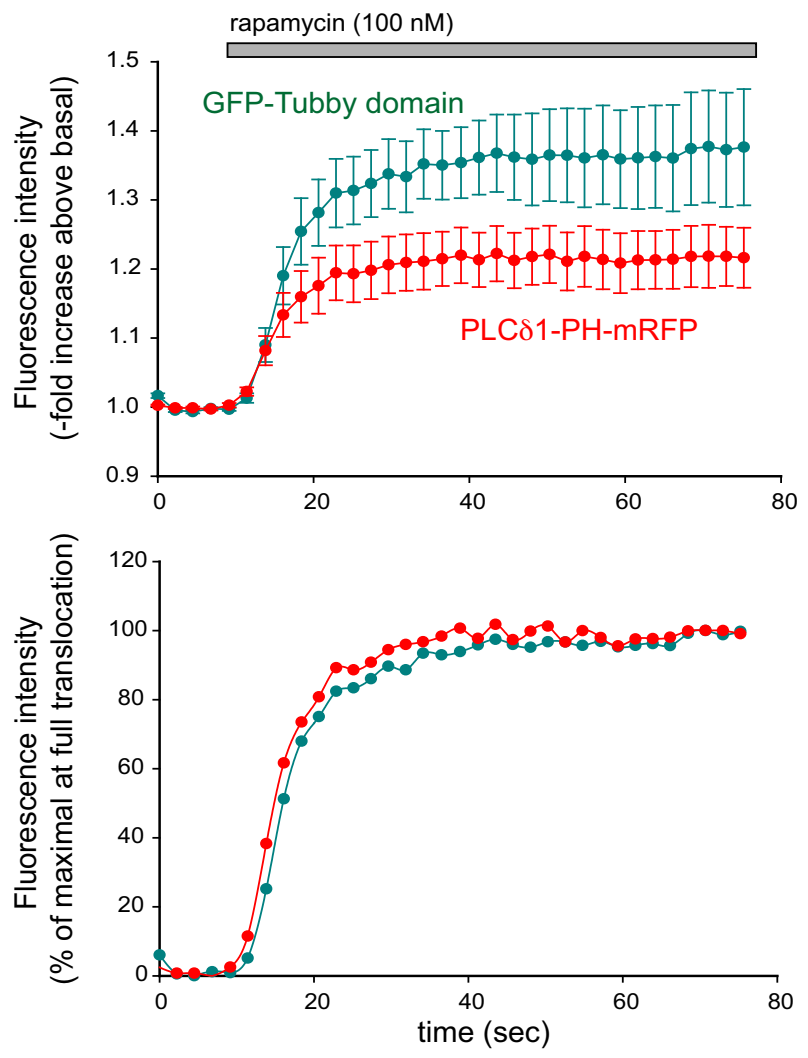

Figure 5

Translocation responses of the Tubby domain and PLC $\delta$ IPH domain after rapid dephosphorylation of Ptdlns (4,5) $\mathbf{P}_{2}$ at the PM. COS-7 cells were co-transfected with the PM-targeted FRB tagged with CFP (not shown), the type-IV 5-ptase domain tagged with cerulean (not shown), the GFP-Tubby-domain and PLC $8 I$ PH-mRFP. After $24 \mathrm{~h}$, live cells were analyzed by confocal microscopy. Addition of $100 \mathrm{nM}$ rapamycin induces translocation of the 5-ptase to the PM, causing a complete loss of both Ptdlns $(4,5) \mathrm{P}_{2}$ reporter localization. Panel $A$ shows representative images before and after rapamycin addition. Panel $B$ shows a full time course of cytoplasmic fluorescence intensity changes based on the average of 10 cells (Mean \pm S.E.M.) expressed as a -fold increase over initial values (upper) or as a percent of the maximal response (lower panel, means are shown only). 
A
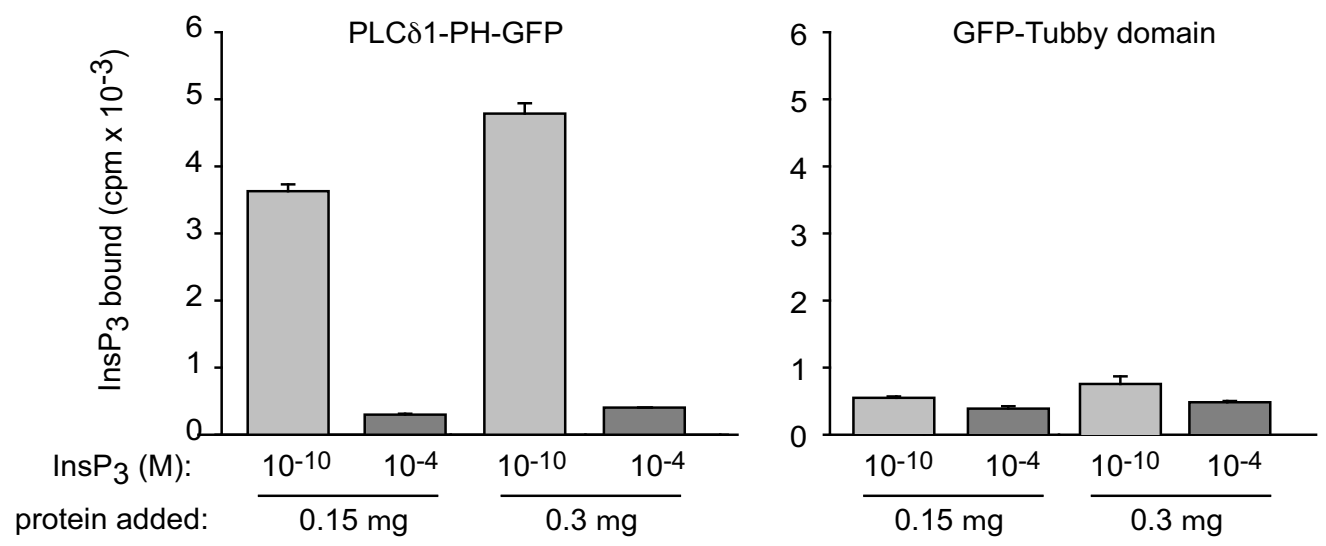

B
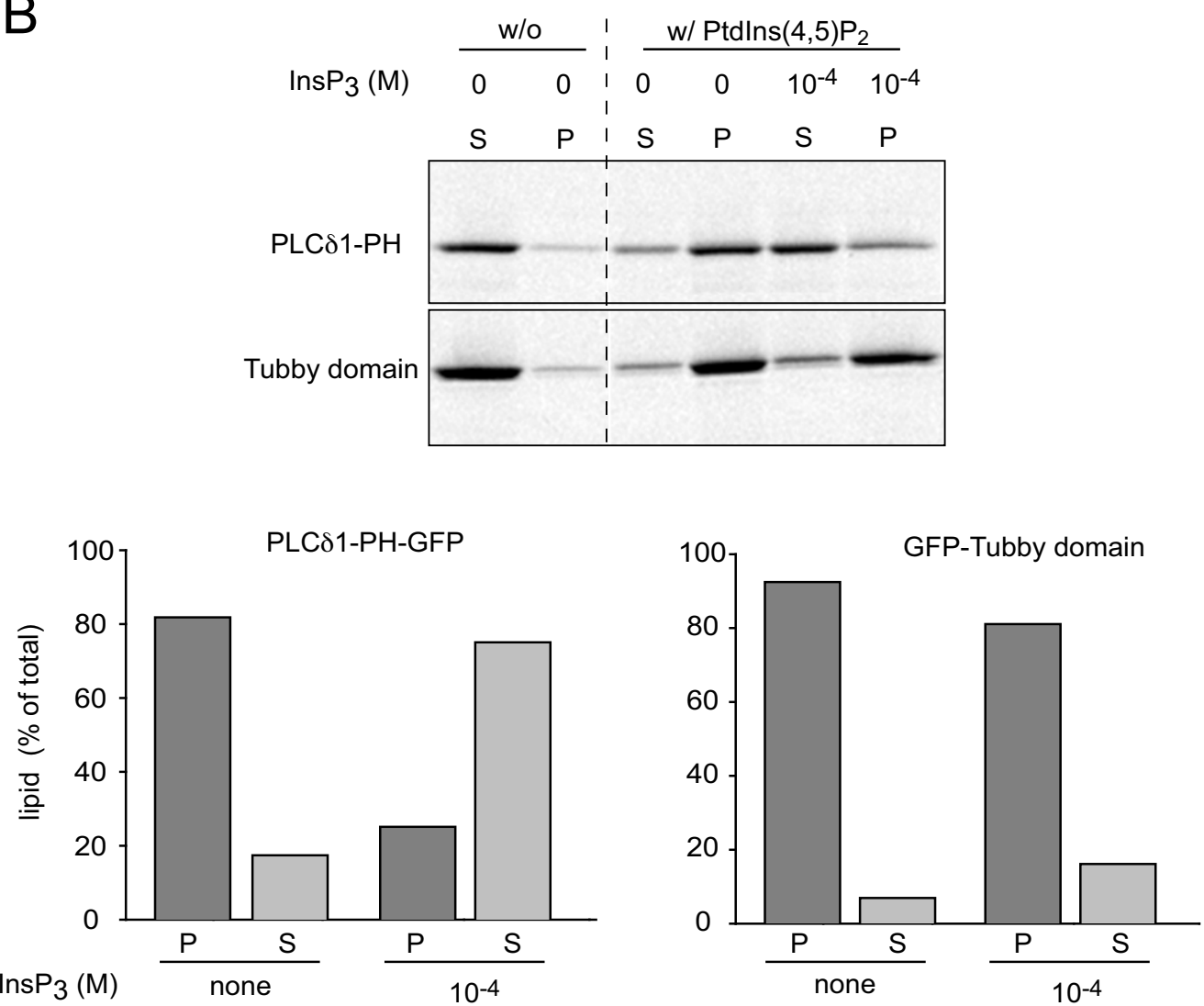

Figure 6

Ins: ${ }_{3}$ and $P$ tdIns $(4,5) P_{2}$ binding of recombinant PLC $\delta$ IPH-GFP and GFP-Tubby-domains. Panel $A$ : Ins $P_{3}$ binding assays were performed at room temperature using $\left[{ }^{3} \mathrm{H}\right]-\operatorname{Ins}(I, 4,5) \mathrm{P}_{3}$ in the presence or absence of the indicated concentrations of unlabeled InsP $\mathrm{P}_{3}$ as detailed under "Experimental Procedures". Means \pm range of 2 experiments performed in duplicate are shown. Panel $B$ shows the binding of recombinant proteins to lipid vesicles containing phosphatidyletanolamine in the absence or presence of Ptdlns $(4,5) \mathrm{P}_{2}$ and Ins $\mathrm{P}_{3}$. Vesicles were pelleted with ultracentrifugation and "S" and "P" represent the soluble (unbound) and pellet-associated (bound) GFP fusion protein, respectively, analyzed by a Phosphorlmager after SDS-PAGE. The result of one of two experiments with identical results is shown. Note the negligible Ins $\mathrm{P}_{3}$ yet very good $\mathrm{Ptdlns}(4,5) \mathrm{P}_{2}$ binding of the Tubby domain. The latter shows only a minor sensitivity to the presence of $\operatorname{lnsP}_{3}$ in contrast to PLC $\delta$ IPH-GFP. 
Recorded cells were grouped into four categories based on their expression level of the respective constructs (mRFP) and their averaged $\mathrm{Ca}^{2+}$ responses were calculated. As shown in Fig. 7, the largest effects on delaying the $\mathrm{Ca}^{2+}$ signal and desynchronizing the response was observed with the p130PH-mRFP construct. It is clear (as observed and reported in [29]) that this construct delays and inhibits the $\mathrm{Ca}^{2+}$ signal very potently. There was very little (if any) difference between the PLC $\delta 1 \mathrm{PH}$ and Tubby domains in their effects on $\mathrm{Ca}^{2+}$ signaling; both domains showed inhibition, but only at higher expression levels. The delay in the $\mathrm{Ca}^{2+}$ rise was slightly bigger in the case of the PLC81PH-mRFP construct (Fig. 7; Table 2 shows the numerical values of the $\mathrm{Ca}^{2+}$ signaling parameters.).

\section{Effects of Ins $(I, 4,5) P_{3}$ buffering on the translocation responses of the two domains}

Since the PLC $1 \mathrm{PH}$ domain has significant InsP $\mathrm{P}_{3}$ affinity, large InsP $\mathrm{P}_{3}$ increases can promote the translocation of the PLC81PH-GFP fusion protein from the membrane to the cytosol [13]. Based on our in vitro InsP ${ }_{3}$ binding experiments, the Tubby domain does not have such an InsP $\mathrm{P}_{3}$ binding property. As shown above and in $[27,29]$, overexpression of the $\mathrm{p} 130 \mathrm{PH}$ domain binds $\mathrm{InsP}_{3}$ and buffers its agonist-induced increases. To determine whether such InsP $_{3}$ buffering has an impact on the translocation of the two studied PtdIns $(4,5) \mathrm{P}_{2}$ reporters, the GFP-tagged versions of either the Tubby-domain or the PLC81PH domain were co-expressed with p130-PH-mRFP in HEK293-AT1 cells and their translocation responses were followed upon the addition of $100 \mathrm{nM}$ AngII. Again, to determine the extent of maximum translocation of the reporters, high concentration of ionomycin $(10 \mu \mathrm{M})$ was added after AngII stimulation. To decrease the speed and the amplitude of InsP $\mathrm{P}_{3}$ changes, these experiments were performed at room temperature as opposed to $35^{\circ} \mathrm{C}$. This condition also ensured that the PLC81PH domain response is not examined at saturation.

As shown in Fig. 8, the translocation responses of the PLC81PH domain and Tubby domain at room temperature showed differences similar to those observed with the $30 \mathrm{nM}$ AngII at $35^{\circ} \mathrm{C}$. The amplitude of the Tubby domain translocation was only partial, while that of PLC81PH was complete relative to the maximal response evoked by high concentration of ionomycin. Comparison of the responses of the respective constructs in the presence or absence of the p130PH-mRFP showed that InsP $\mathrm{P}_{3}$ buffering in these cells had only small (if any) effect on the translocation responses. In both cases the amplitude of the AngII response was slightly smaller, slower and more prolonged in the $\mathrm{p} 130 \mathrm{PH}-\mathrm{mRFP}$ expressing cells, which was consistent with a buffered $\mathrm{InsP}_{3}$ (and resultant cytoplasmic $\mathrm{Ca}^{2+}$ kinetics). The fact that both constructs showed the same alteration of the translocation responses suggests that it is the slight distortion of the $\mathrm{Ca}^{2+}$ signal rather than the buffered InsP $\mathrm{P}_{3}$ change per se that was responsible for these changes. It is important to note that in contrast to the ATP-stimulated COS-7 cells in which PLC activation is modest (and cannot even be detected by $\mathrm{PH}$-domain translocation), the $\mathrm{InsP}_{3}$ changes and the translocation responses are a lot more robust in the AngIIstimulated HEK293-AT1 cells and, in the latter, p130PHexpression has only a modest effect on the AngII induced $\mathrm{Ca}^{2+}$ signal (Varnai and Balla unpublished observations). However, while the COS-7 cells are ideally suited to determine the effects of InsP $_{3}$ binding or impaired substrate access of PLC when the cells express the PtdIns $(4,5) \mathrm{P}_{2}$ reporters, the HEK293-AT1 cells are more useful to determine the effects of InsP $\mathrm{P}_{3}$ buffering on reporter translocation because their supramaximal $\mathrm{InsP}_{3}$ responses can be significantly blunted before affecting their cytoplasmic $\mathrm{Ca}^{2+}$ signals. These results together suggested to us that at least in our cellular model, the $\mathrm{InsP}_{3}$ changes primarily affect the translocation responses of either domain via their effects on cytoplasmic $\mathrm{Ca}^{2+}+$ PLC rather than via direct displacement.

\section{Discussion}

The present study was designed to widen the repertoire of phosphoinositide binding modules capable of providing information on PtdIns $(4,5) \mathrm{P}_{2}$ changes in mammalian cells. So far most such studies have utilized the $\mathrm{PLC} \delta_{1} \mathrm{PH}-$ GFP construct, which does not detect PtdIns $(4,5) \mathrm{P}_{2}$ in cellular location other than the PM and also could suffer from overestimating PtdIns $(4,5) \mathrm{P}_{2}$ decreases, due to a displacing effect of Ins $\mathrm{P}_{3}$. The extent of this distortion may vary from cell-type to cell-type and also depends on expression levels [30] and, therefore, has been a matter of dispute $[10,31]$.

In a thorough recent study, several PH domains of S.cerevisiae have been described as capable of phosphoinositide binding, although only one, the Num1p PH domain, showed decent PtdIns $(4,5) \mathrm{P}_{2}$ binding specificity based on several in vitro binding assays [16]. However, in vivo studies in yeast mutants that allowed specific manipulations of phosphoinositides concluded that PM targeting of several of these PH domains (Num1p, Cla4p, Skm1p, Slm1p, and SIm2p) showed PtdIns $(4,5) \mathrm{P}_{2}$ dependence, while the membrane recruitment of the Opy1p-PH domain was found to be independent of phosphoinositides. We extended these studies to mammalian cells and characterized the PtdIns $(4,5) \mathrm{P}_{2}$ dependence of the membrane association of these $\mathrm{PH}$ domains using controlled manipulations of PtdIns $(4,5) \mathrm{P}_{2}$. As described before, all of these PH domains showed PM localization and none was recruited to any intracellular membranes, although some (such as the Opy1p PH domain) also showed nuclear or nucleolar localization. The expression of some 

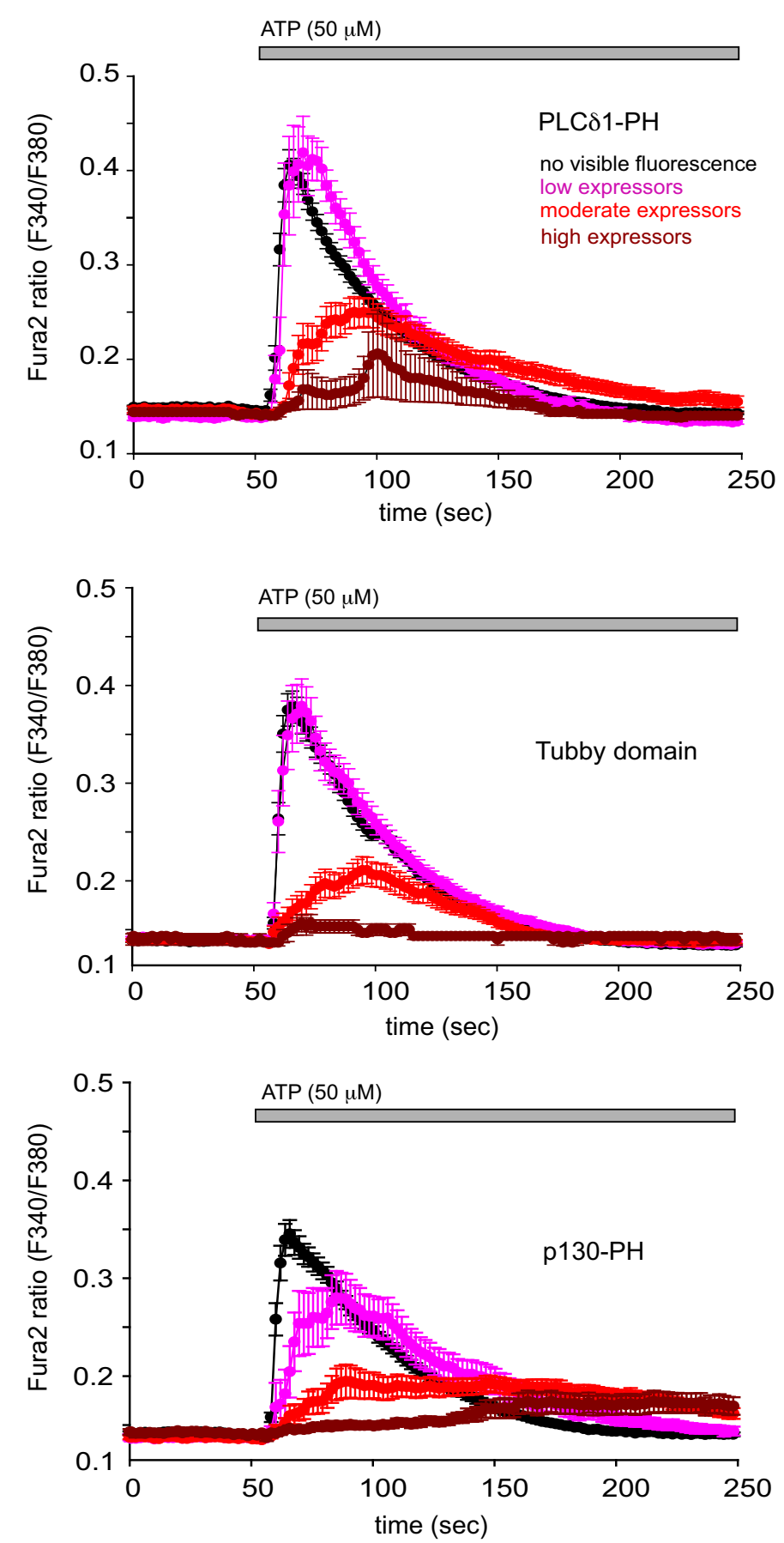

Figure 7

Inhibition of agonist-induced $\mathrm{Ca}^{2+}$ signaling by expressed mRFP-Tubby-domain, PLC $\delta$ IPH-mRFP and $\mathrm{pI} 30$ -

PH-mRFP. COS-7 cells were transfected with the indicated mRFP fusion constructs, and their cytosolic $\mathrm{Ca}^{2+}$ responses were analyzed by ratiometric $\mathrm{Ca}^{2+}$ imaging using Fura2. The amount of fluorescent protein was determined after the release of all membrane bound constructs by the addition of high concentraction of ionomycin at the end of each experiment. ATP-induced $\mathrm{Ca}^{2+}$ responses were grouped into four categories according to expression levels of the red fluorescence and the responses were averaged (see Table 2 for these values in each group in arbitrary units). Note that each construct interferes with the $\mathrm{Ca}^{2+}$ signal in these COS-7 cells where the ATP-induced PLC activation and InsP $\mathrm{P}_{3}$ increase is relatively modest. Such inhibitory effects are substantially smaller in HEK293-ATI cells that show robust PLC activation (see Fig. 8). Table 2 shows the numerical values of the $\mathrm{Ca}^{2+}$ signaling parameters. 


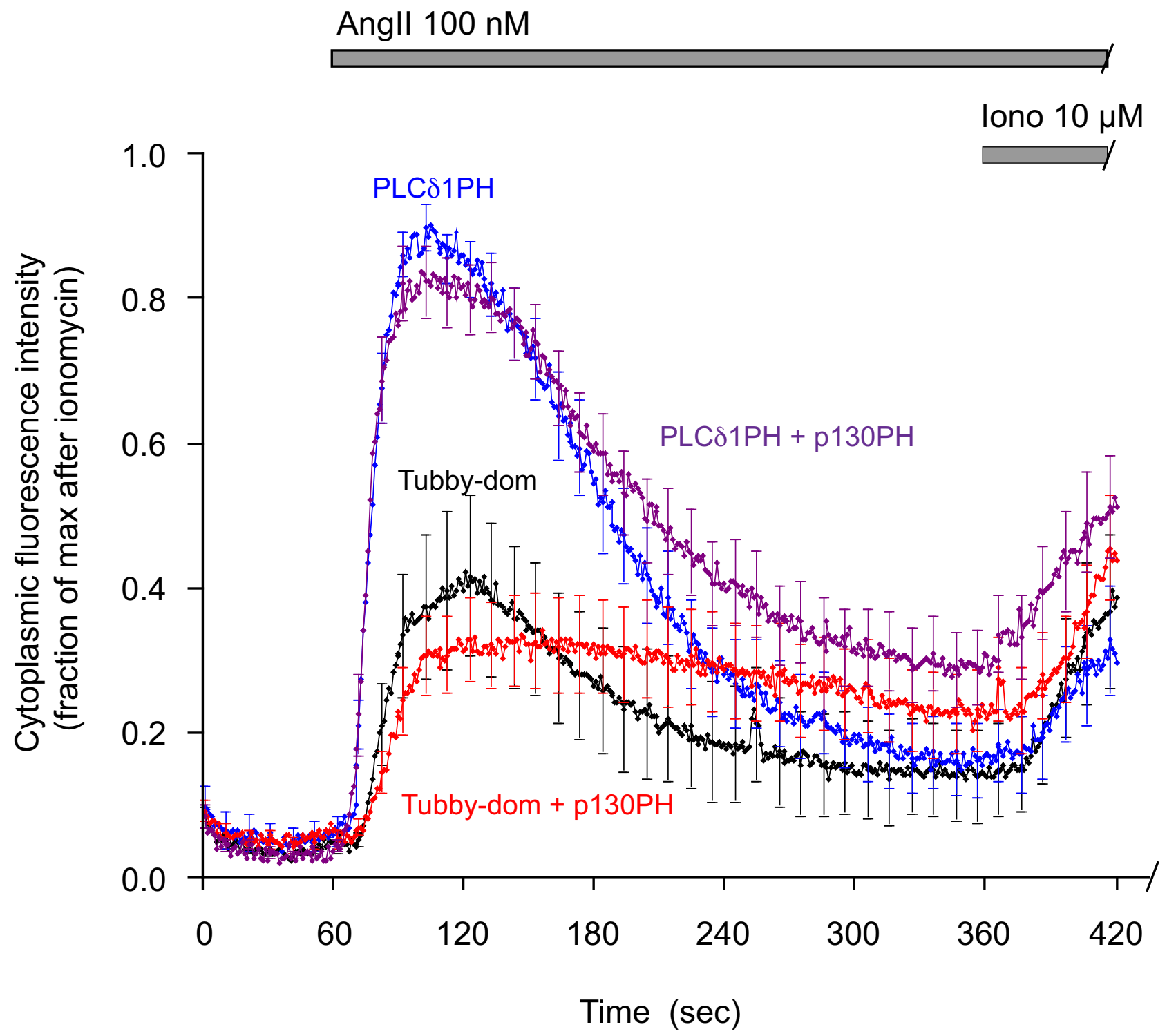

Figure 8

Effects of InsP $\mathrm{P}_{3}$ buffering on Angll-induced Tubby-domain and PLC $\delta$ I PH translocation responses. HEK293-ATI cells were transfected with the indicated GFP reporter constructs alone or together with pl $30 \mathrm{PH}-\mathrm{mRFP}$. After 24 hours, cells were examined in a Zeiss Live 5 DuoScan confocal microscope at room temperature. Cells were stimulated with $100 \mathrm{nM}$ Angll at 60 second followed by $10 \mu \mathrm{M}$ ionomycin at $360 \mathrm{sec}$. Data were collected at I fps rate and the cytoplasmic fluorescence intensity was analyzed in selected regions of interest outside the nucleus. Values were normalized for minimum and maximum fluorescence values for each run and these values were averaged. Means \pm S.E.M. are shown obtained from: $n=10$ (Tubby domain alone), $\mathrm{n}=12$ (PLC $\delta \mathrm{IPH}$ alone), $\mathrm{n}=2 \mathrm{I}$ (Tubby domain $+\mathrm{pl} 30 \mathrm{PH}-\mathrm{mRFP})$ and $\mathrm{n}=20$ (PLC $\delta \mathrm{IPH}+\mathrm{pI} 30 \mathrm{PH}-\mathrm{mRFP})$ cells. The traces were truncated at $420 \mathrm{sec}$ to better illustrate the Angll-induced changes.

of these PH domains (namely the Num1p) was very low and required switching the GFP around to improve expression. Adding a nuclear export signal to the GFPOpy1p-PH construct allowed a better assessment of its membrane binding properties. Remarkably, the behavior of these constructs did not completely match with that described in yeast cells. For example, the PH domains of
Cla4p, Skm1p, and SIm2p showed no detectable decrease during PLC activation or after elimination of PtdIns $(4,5) \mathrm{P}_{2}$ via a 5-phosphatase. In contrast, the Opy1p $\mathrm{PH}$ domain followed the changes in PtdIns $(4,5) \mathrm{P}_{2}$ in spite of its apparent failure to do so in yeast. Unfortunately, the Num1p PH domain that binds PtdIns $(4,5) \mathrm{P}_{2}$ with the highest specificity in yeast cells did not show any features 
Table 2: $\mathrm{Ca}^{2+}$ signaling parameters in ATP-stimulated COS-7 cells expressing either one of the mRFP-Tubby-domain, PLC $\delta$ I PH-mRFP and $\mathrm{p} \mid 30-\mathrm{PH}-\mathrm{mRFP}$ proteins

\begin{tabular}{llll}
\hline Construct & $\begin{array}{l}\text { mRFP fluorescence } \\
(\mathbf{A U})\end{array}$ & $\begin{array}{l}\mathbf{T}_{1 / 2} \text { activation* } \\
(\mathbf{s e c})\end{array}$ & $\mathbf{N}=$ \\
\hline Tubby-domain & $<100$ & $6.0 \pm 0.3 * *$ & 109 \\
& $101-1000$ & $6.0 \pm 1.8$ & 31 \\
& $1001-5000$ & $13.5 \pm 3.5$ & 40 \\
& $5001-10000$ & $12.0 \pm 1.5$ & 4 \\
\hline PLC $\delta$ IPH & $<100$ & $3.5 \pm 0.4$ & 99 \\
& $101-1000$ & $6.5 \pm 1.1$ & 20 \\
& $1001-5000$ & $12.5 \pm 3.9$ & 34 \\
& $5001-10000$ & $18.0 \pm 6.1$ & 5 \\
\hline \multirow{2}{*}{ PI30-PH } & $<100$ & $3.5 \pm 0.4$ & 91 \\
& $101-1000$ & $12.0 \pm 4.9$ & 16 \\
& $1001-5000$ & $19.5 \pm 5.3$ & 39 \\
& $5001-10000$ & $>100$ & 17 \\
\hline
\end{tabular}

* The lag time of the $\mathrm{Ca}^{2+}$ response was defined as the time it takes for a cell to reach half-maximum of its $\mathrm{Ca}^{2+}$ peak after addition of 50 $\mu$ M ATP.

**Values are calculated from cells expressing the mRFP-tagged proteins at the indicated intensities. Note the largest effects of the pl30-PH-mRFP protein that does not bind to the membranes but binds Ins $\mathrm{P}_{3}$ with comparable affinity to the PLC $\delta I \mathrm{PH}-\mathrm{mRFP}$ [27].

that would make it a great substitute for PLC81PH-GFP. First, its expression was modest and in cells showing higher expression, it created bright vesicular structures budding off the plasma membrane. Moreover, it showed only a modest translocation from the membrane to the cytosol after PLC activation. One of the probes, the Slm1p-PH appeared to be a mixed reporter of PtdIns $(4,5) P_{2}$ and PtdIns4P in the membrane. This domain was only partially displaced from the membrane after 5-phosphatase recruitment, suggesting that it may still be binding to the PtdIns $4 P$ that is generated by the 5phosphatase.

The discrepancy between the probes behavior in the yeast and mammalian cells is not unprecedented. For example, we did not observe Golgi localization of the PtdIns4P reporter OSH2-PH in mammalian cells [22] while it clearly showed the Golgi pool in yeast [16,32]. This is suggestive of a more complex mechanism of membrane recruitment of the $\mathrm{PH}$ domains, involving not only phosphoinositides but probably other proteins (or anionic lipids) as interacting partners. Whether a mammalian protein can substitute for the yeast protein in the proteinprotein interaction with a yeast $\mathrm{PH}$ domain probably varies from one domain to another, making the outcome difficult to predict. Nonetheless, these studies have concluded that none of the predicted PtdIns $(4,5) \mathrm{P}_{2}$ recognizing probes from the yeast $\mathrm{PH}$ domain collection have detected other pools of this lipid in intracellular compart- ments and none has shown any obvious advantage over the mammalian ones to be used in imaging studies. This is in contrast to PtdIns $4 P$ recognizing $\mathrm{PH}$ domains of the yeast that have been successfully used in mammalian cells [22,32,33].

Another PtdIns $(4,5) \mathrm{P}_{2}$ reporter characterized in this study was the Tubby domain of the mammalian transcription factor Tubby protein. The Tubby domain was described as a high affinity $\operatorname{Ptd} I n s(4,5) \mathrm{P}_{2}$ binding module found at the C-terminus of the Tubby protein and being responsible for its lipid binding and membrane localization [18]. It was also claimed as one that does not bind InsP $_{3}$, although direct experimental evidence for this has not been available in published literature. The Tubby domain has already been used as a $\operatorname{PtdIns}(4,5) \mathrm{P}_{2}$ reporter [19] and two recent studies have examined the usefulness of the full-length Tubby protein [20] or a mutant form of the Tubby domain [21] as a $\operatorname{PtdIns}(4,5) \mathrm{P}_{2}$ probe in comparative studies similar to ours. Our results with the wild-type Tubby domain had several similarities, but also notable differences to the results described in those studies.

Firstly, both studies found that the Tubby protein as well as the Tubby domain has higher affinity to the PM than PLC81PH-GFP. In fact, the wild-type Tubby domain was found to have high enough affinity that it did not show agonist-induced responses in many cells prompting the authors to create a mutant $(\mathrm{R} 332 \mathrm{H})$ with a reduced affinity that was found useful in their studies [21]. Interestingly, in the cells used in our studies the same mutation completely eliminated the membrane localization of the Tubby domain (Szentpetery and Balla unpublished observation) making it unsuitable for further studies. We did not have an explanation for this discrepancy other than the different fluorescent proteins used in the two studies and that the placing of the fluorescent protein relative to the Tubby domain was different. Quinn et al. used eYFP, while we used eGFP fusion constructs and we used GFP in front of the Tubby domain whereas the Quinn study found the mutant Tubby construct having YFP at its C-terminus a more suitable one. Since the dimerization tendency of YFP is larger than that of GFP [34] it is possible that the higher apparent affinity of the constructs in the Quinn study reflects a dimerization of the fusion proteins, which could explain these differences. Indeed, when we generated the same Tubby domain constructs fused to YFP (still the fluorescent protein in front) we found that the $\mathrm{R} 332 \mathrm{H}$ mutant did show some membrane localization, especially in COS-7 cells but not as much as shown in the Quinn study (Szentpetery and Balla, unpublished observation). Although this slight localization does not match those described by Quinn et al., the higher dimerization tendency of YFP still may play into the apparent affinity of the mutant Tubby construct. 
Nevertheless, a higher affinity of the full-length Tubby protein (fused to eGFP) to the membrane was also shown in the Nelson study and manifested as a rightward shift (compared to the PLC81PH-GFP response) in the doseresponse curve with muscarinic agonist measuring the translocation of the Tubby protein from the membrane to the cytosol. Our results are in good agreement with these studies as we also found a significantly higher fraction of the Tubby domain at the PM than with PLC 1 PH, and documented a substantial difference between the agonistsensitivities of the Tubby domain and PLC 1 PH-GFP translocation responses. Moreover, our FRAP analysis showed that the dissociation of the Tubby domain from the membrane is significantly slower than that of the PLC81PH-GFP.

All three studies showed that Tubby domain (or the fulllength Tubby protein) displayed no sensitivity to $\mathrm{InsP}_{3}$ in agreement with the original claims [18]. The present study also showed it with direct binding assays using recombinant Tubby domains. Quinn et al. showed that diffusion of $\mathrm{InsP}_{3}$ into the patch pipette caused no translocation of the Tubby domain mutant, while making the PLC81PH-GFP fully translocate to the cytosol [21]. The Nelson study, on the other hand, used overexpression of an InsP ${ }_{3} 3$-kinase to limit InsP ${ }_{3}$ increases as described in their earlier studies [35,36]. They found that in contrast to PLC81PH-GFP, the Tubby domain translocation after agonist stimulation was insensitive to $\mathrm{InsP}_{3} 3$-kinase overexpression [20]. However, any reduction in Ins $\mathrm{P}_{3}$ increase (whether converted to InsP ${ }_{4}$, or InsP $\mathrm{P}_{2}$ or being buffered by an $\mathrm{InsP}_{3}$ binding domain) also reduces the $\mathrm{Ca}^{2+}$ signal and as a corollary will limit PLC activation. This was most likely the case in the Quinn study where overexpression of the $\mathrm{InsP}_{3}$ 5-phosphatase eliminated the translocation responses of both PtdIns $(4,5) \mathrm{P}_{2}$ probes [21]. This study also found that the Tubby domain translocation was slightly more sensitive to inhibition by $\mathrm{Ca}^{2+}$ depletion than that of the PLC81PH construct. This finding agreed with our observation that the Tubby domain had a slower response to the cytoplasmic $\mathrm{Ca}^{2+}$ increase than the PLC81PH-GFP, consistent with an increased "resistance" of the Tubby-domain-covered PtdIns $(4,5) \mathrm{P}_{2}$ to PLC-mediated hydrolysis. It is worth noting that both the Quinn study and ours used HEK293 cells.

In contrast to these findings, a striking reduction was observed in neuroblastoma cells in the translocation responses of the PLC 1 PH domain, but not those of the Tubby protein, when InsP $\mathrm{P}_{3} 3$-kinase was expressed, with a strong reduction in the cytoplasmic $\mathrm{Ca}^{2+}$ response [20]. This seemingly contradicted the higher $\mathrm{Ca}^{2+}$ requirement of the Tubby domain translocation also observed in that same study. One possible explanation for this apparent contradiction is, if the magnitudes of InsP $\mathrm{P}_{3}$ increases are much larger in the neuronal cells used in the Nelson study than those observed in HEK293 cells. This is not an unreasonable assumption, since N1E-115 neuroblastoma cells require much higher InsP $\mathrm{P}_{3}$ increases to induce $\mathrm{Ca}^{2+}$ signaling than other cell types [37]. In search of an explanation for this unique feature, Watras et al. has identified a protein in neurons that binds the $\mathrm{InsP}_{3}$ receptor to significantly decrease its InsP $\mathrm{P}_{3}$ sensitivity [37]. This could make neuroblastoma cells (and perhaps other neuronal cell lines) less sensitive to $\mathrm{InsP}_{3}$ increases requiring them to generate a lot more $\mathrm{InsP}_{3}$ in response to agonists that could significantly displace the PLC $\delta 1$ PH-GFP from the $\mathrm{PM}$. Additionally, any change in the relative proportion of PtdIns $(4,5) \mathrm{P}_{2}$ vs. InsP $\mathrm{P}_{3}$ can contribute to a larger InsP $\mathrm{P}_{3}$ sensitivity of the PLCd1PH translocation as demonstrated in mathematical modeling studies [30].

The question remains whether the tighter binding of the Tubby domain to the membrane is related to its lower affinity to Ins $\mathrm{P}_{3}$. A significant amount of free $\mathrm{InsP}_{3}$ present in the cytosol could indeed partially displace the PLC61PH-GFP from the membrane while not affecting the binding of the Tubby domain. However, overexpression of either the InsP $\mathrm{P}_{3}$ kinase [20], the $\mathrm{InsP}_{3} 5$-phosphatase [21] or an $\mathrm{InsP}_{3}$ binding domains had little if any impact on the basal localization of the PLC 81 PH-GFP. Moreover, the slightest increases in free $\mathrm{InsP}_{3}$ are immediately detected by the InsP3-R in the form of $\mathrm{Ca}^{2+}$ release. Therefore, we do not favor an explanation that assumes significant free $\mathrm{InsP}_{3}$ levels in the cytoplasm of quiescent cells. We would rather assume that the tighter binding of the Tubby domain to the membrane reflects a genuinely higher affinity either to $\operatorname{PtdIns}(4,5) \mathrm{P}_{2}$ itself, or to the lipid together with some additional membrane component(s). This is consistent with the slower dissociation rate as well as the stronger resistance of the $\operatorname{PtdIns}(4,5) \mathrm{P}_{2}$ pool covered with the Tubby domain to respond to PLC activation. The fact that the ${ }^{32} \mathrm{P}$-phosphate or $\left[{ }^{3} \mathrm{H}\right]-m y o$-inositol labeled HEK293-AT1 cells (the same cells used in this study) lose about $80-90 \%$ of their labeled PtdIns $(4,5) \mathrm{P}_{2}$ within $30 \mathrm{sec}$ of stimulation with $100 \mathrm{nM}$ AngII [22], yet the Tubby domain responds only in a fraction of cells stimulated with the same dose of agonist, suggest that the Tubby domain probably underestimates the changes in PtdIns $(4,5) \mathrm{P}_{2}$ because of its interference with PLC activation (PLC breaks down a larger fraction of PtdIns $(4,5) \mathrm{P}_{2}$ that is not bound to the Tubby domain). Therefore, while the PLC81PH domain may overestimate PLC activation because of its $\mathrm{InsP}_{3}$ sensitivity, the Tubby domain may underestimate it because of its higher apparent PtdIns $(4,5) \mathrm{P}_{2}$ affinity. In fact, in the cells used in these studies (HEK293-AT1 and COS-7), the inhibitory effects of the two domains on $\mathrm{Ca}^{2+}$ signaling were very comparable: in one case due to the combined effects on InsP $\mathrm{P}_{3}$ quenching and PtdIns $(4,5) \mathrm{P}_{2}$ binding (PLC 1 PH-GFP), 
while in the other case because of a tighter $\operatorname{PtdIns}(4,5) \mathrm{P}_{2}$ binding (Tubby domain). The slight delay in the onset of $\mathrm{Ca}^{2+}$ rise caused by the expression of the PLC $81 \mathrm{PH}-\mathrm{mRFP}$ but not the mRFP-Tubby domain is certainly another indication that the PLC $1 \mathrm{PH}$ domain binds InsP $\mathrm{P}_{3}$. Importantly, we did not see a significant difference between the two domains in their sensitivity to expression of InsP $_{3}$ buffering constructs, essentially both being affected probably due to interference with the $\mathrm{Ca}^{2+}$ signal.

An important observation of the present study was the delayed Tubby response relative to that of the PLC81PH domain during PLC activation but not when the 5-phosphatase was recruited to the PM. This finding may simply suggest that the $\mathrm{InsP}_{3}$ increase does indeed contribute to PLC81PH translocation. However, it is also possible that the endogenous PLC activation mechanism is more sensitive to masking of PtdIns $(4,5) \mathrm{P}_{2}$ by the Tubby domain than the catalysis by the recruited 5-phosphatase. The fact that the Tubby domain does not bind the soluble headgroup, InsP $\mathrm{P}_{3}$, even though it binds $\operatorname{PtdIns}(4,5) \mathrm{P}_{2}$ with higher affinity, already suggests that the binding force of the Tubby domain must receive significant contributions from interactions with the glycerol backbone. If this were indeed the case, the Tubby domain would obscure the phosphodiester group more and with that could block the access of PLC to this site.

Lastly, these studies have shown a perfect example of how the same lipid, PtdIns $(4,5) \mathrm{P}_{2}$ can regulate several effectors in the same cell simultaneously and yet differently. Just by having two different apparent affinities of two reporters used in the present study - mimicking two endogenous binding partners - is sufficient to elicit a differential response to the same PLC activation. This was also convincingly demonstrated in the experiments where the Kir6.2 $\mathrm{K}_{\text {ATP }}$ channel [20] or the KCNQ M-channel [38] (two known PtdIns $(4,5) \mathrm{P}_{2}$ regulated $\mathrm{K}^{+}$channels) responses were correlated with $\operatorname{PtdIns}(4,5) \mathrm{P}_{2}$ changes assessed by the fluorescent reporters.

There are several other conclusions highlighted by these studies. Firstly, all probes based on binding to PtdIns $(4,5) \mathrm{P}_{2}$ (or to any other lipid) show some bias depending on its affinity to the lipid. Secondly, the experimental system may also determine the extent to which the probe manifests its limitation. Thirdly, even the fluorescent protein used a fusion partner can modify the utility of a bioprobe. These should be all reminders that we need to be cautious of selecting a probe and consider it as "the" gold standard.

\section{Conclusion}

The present study analyzed a set of PtdIns $(4,5) \mathrm{P}_{2}$ reporters some selected from yeast PH domains and one compris- ing of the Tubby domain of the transcription factor, Tubby. All of these fluorescent probes confirmed that PtdIns $(4,5) \mathrm{P}_{2}$ shows highest abundance in the PM and that this lipid is undetectable in intracellular membranes. Most of the yeast-derived $\mathrm{PH}$ domains were found less useful, some expressing at low levels or showing weak membrane localization, others causing membrane blebbing, Detailed comparison of the PLC 1 PH-GFP and the Tubby domain showed that both reporters are suitable to follow PtdIns $(4,5) \mathrm{P}_{2}$ changes in living cells, but the Tubby domain is less sensitive because of its higher affinity to PtdIns $(4,5) \mathrm{P}_{2}$. PLC $81 \mathrm{PH}$ domain was found to be the most sensitive reporter but because of its binding to $\operatorname{InsP}_{3}$ some of its translocation is caused by $\mathrm{InsP}_{3}$ increases that can become a problem especially in certain cell types. The differential responses of the two domains to PtdIns $(4,5) \mathrm{P}_{2}$ changes helps us understand and envision the principles of inositide regulation of multiple effectors.

\section{Methods \\ Materials}

AngiotensinII (human octapeptide) was from Bachem (Torrance, CA), rapamycin was from Calbiochem (San Diego, CA) or LC Biochemicals (Woburn, MA). All other chemicals were of the highest purity grades.

\section{DNA constructs}

The PLC81-PH-GFP and its color variants and the p130PH-mRFP constructs have been described previously $[24,27]$. The C-terminal (243-505) Tubby domain of the mouse Tubby protein fused at its N-terminus to GFP was a generous gift from Dr. L. Shapiro (Mount Sinai School of Medicine, NY) [18]. The Tubby domain was also subcloned into the mRFP-C1 vector using the SalI-BamH1 sites. For bacterial expression of the recombinant proteins, the GFP-Tubby-domain was amplified with the primer pairs, 5'-ATATCATATGGTGAGCAAGGGCGAGGAGC-3' and 5'-ATATGCGGCCGCCTCGCAGGCCAGCTTGCTGTC-3' and the PCR product cloned into the pET-23a bacterial expression vector between the NdeI and NotI sites. The PLC $\delta_{1}$-PH-GFP fusion protein for bacterial expression has been described previously [27].

\section{Transfection of cells for confocal microscopy and intracellular $\mathrm{Ca}^{2+}$ measurements}

For single cell analysis HEK293-AT1 (a HEK293 cell line stably expressing the rat $\mathrm{AT}_{1 \mathrm{a}}$ angiotensin receptor) or COS-7 cells were used. Cells were plated onto $25-\mathrm{mm}$ diameter circular glass cover slips at a density of $3 \times 10^{5}$ cells/dish one day before transfection with plasmid DNAs (0.5-1 $\mu \mathrm{g} / \mathrm{dish})$ using the Lipofectamine2000 reagent (Invitrogen) and OPTI-MEM (Invitrogen). One day after transfection, cells were washed twice with a modified Krebs-Ringer solution, containing $120 \mathrm{mM} \mathrm{NaCl}, 4.7 \mathrm{mM}$ $\mathrm{KCl}, 1.2 \mathrm{mM} \mathrm{CaCl}_{2}, 0.7 \mathrm{mM} \mathrm{MgSO}_{4}, 10 \mathrm{mM}$ glucose, 10 
$\mathrm{mM}$ Na-Hepes, pH 7.4 and the coverslip was placed into a metal chamber that was mounted on a heated stage with the medium temperature kept at $33^{\circ} \mathrm{C}$. Note that some experiments were performed at room temperature. Cells were incubated in $1 \mathrm{ml}$ of the Krebs-Ringer buffer and the stimuli were added in $200 \mu \mathrm{l}$ warm buffer removed from the cells. Cells were examined in an inverted microscope under a $60 \times$ oil-immersion objective (LSM 510-META; Carl Zeiss MicroImaging, Inc.) equipped with an objective heater (Bioptech).

\section{FRAP analysis}

FRAP experiments were performed in a Zeiss Live5 DuoScan Confocal Microscope system in which continuous fast scanning is possible while photobleaching with another laser. Images were collected at 0.1-0.5 s intervals and selected regions in the PM were photobleached at $100 \%$ power of the bleaching laser. After background subtraction, two parameters were calculated from the intensity curves obtained in the center of a larger bleached area: the mobile fraction (MF), which represents the percent recovery after photobleaching compared to the initial fluorescence value before photobleaching; and a $\mathrm{T}_{1 / 2}$ value, which is the time required to reach half maximal recovery.

\section{Cytoplasmic $\mathrm{Ca}^{2+}$ studies}

For $\mathrm{Ca}^{2+}$ measurements, cells were loaded with $3 \mu \mathrm{M}$ fura2/AM (45 min, room temperature) in a Hepes-based M199, containing $200 \mu \mathrm{M}$ sulfinpyrazone and $0.06 \%$ pluronic acid. After loading, $\mathrm{Ca}^{2+}$ measurements were performed at room temperature in the same modified KrebsRinger solution containing no $\mathrm{Ca}^{2+}$. An inverted microscope (IX70; Olympus) equipped with a Lambda DG-4 illuminator (Sutter Instruments) and a Micromax 1024 BFT camera (Roper Scientific) and the appropriate filter sets were used for $\mathrm{Ca}^{2+}$ analysis. Data acquisition and processing were performed by the MetaFluor software (Molecular Devices).

\section{In vitro Ins $(I, 4,5) P_{3}$ and $P$ tdIns $(4,5) P_{2}$ binding assays}

Recombinant proteins were produced in the BL-21-DE3 strain of Escherichia coli (Invitrogen). Bacterial cells were grown to $\mathrm{A}_{600}: 0.6$ at $37^{\circ} \mathrm{C}$ and induced with $300 \mu \mathrm{M}$ isopropyl-1-thio- $\beta$-D-galactopyranoside (IPTG) at $18-20^{\circ} \mathrm{C}$ for $7 \mathrm{~h}$. Bacterial lysates were prepared by sonication in lysis buffer (20 mM NaCl and $20 \mathrm{mM}$ Tris, pH 8.0) followed by centrifugation at $10,000 \times \mathrm{g}$ for $30 \mathrm{~min}$ at $4^{\circ} \mathrm{C}$. The supernatant was incubated with $\mathrm{Ni}^{2+}$-NTA-agarose beads (Qiagen) in the presence of $5 \mathrm{mM}$ imidazole for 1 $\mathrm{h}$ at $4^{\circ} \mathrm{C}$. The beads were washed three times with lysis buffer, and the recombinant proteins were eluted with the same buffer containing $1 \mathrm{M}$ imidazole. The concentration of recombinant proteins was assessed by quantifying the bands of Coomassie Blue-stained SDS gel containing the recombinant proteins using bovine serum albumin as a standard.

The in vitro Ins $\mathrm{P}_{3}$ binding assay and the $\mathrm{InsP}_{3}$ displacement from PtdIns $(4,5) \mathrm{P}_{2}$ binding were performed as described previously [27]. Briefly, the incubation buffer of the in vitro InsP $\mathrm{P}_{3}$ binding assay contained $50 \mathrm{mM} \mathrm{Na-}$ Hepes, pH 7.4, $50 \mathrm{mM} \mathrm{KCl,} 0.5 \mathrm{mM} \mathrm{MgCl}_{2}$, and $0.01 \mathrm{mM}$ $\mathrm{CaCl}_{2}$. About $0.2 \mu \mathrm{g}$ of soluble recombinant proteins was incubated in $50 \mu \mathrm{l}$ of this buffer with $0.74 \mathrm{kBq}(0.5 \mathrm{nM})$ $\left[{ }^{3} \mathrm{H}\right] \mathrm{Ins}(1,4,5) \mathrm{P}_{3}$ with increasing concentrations of unlabeled Ins $\mathrm{P}_{3}$ for $10 \mathrm{~min}$ on ice. The binding reaction was terminated by adding $5 \mu \mathrm{l}$ of human $\gamma$-globulin $(10 \mathrm{mg} /$ $\mathrm{ml}$ ) and $50 \mu \mathrm{l}$ polyethylene glycol 6000 (30\%). Tubes were left on ice for $5 \mathrm{~min}$ and then centrifuged at 10,000 $\times \mathrm{g}$ for $10 \mathrm{~min}$. The pellets were dissolved in $0.1 \mathrm{ml}$ of $2 \%$ SDS, and their radioactivity was counted in a liquid scintillation counter.

Binding to phospholipids was performed with mixed lipid vesicles. $110 \mu \mathrm{g}$ of PtdIns $(4,5) \mathrm{P}_{2}$ and $1.4 \mathrm{mg}$ of phosphatidylethanolamine (bovine liver; Avanti) were mixed and dried under a nitrogen stream followed by high vacuum, and the dried mixtures were suspended to a final total lipid concentration of $2 \mathrm{mM}$ (PE) in $20 \mathrm{mM}$ Hepes, $\mathrm{pH}$ 7.2, $100 \mathrm{mM} \mathrm{NaCl}, 2 \mathrm{mM}$ EGTA, $0.1 \mu \mathrm{g} / \mathrm{ml}$ bovine serum albumin by bath sonication. $5 \mu$ l of the purified GFP fusion protein $(\sim 1 \mu \mathrm{g})$ and $5 \mu \mathrm{l}$ of buffer or Ins $(1,4,5) \mathrm{P}_{3}$ were added to $90 \mu$ of phospholipid vesicles. The reaction mixture was incubated at $30^{\circ} \mathrm{C}$ for $10 \mathrm{~min}$ followed by ultracentrifugation at $85,000 \mathrm{rpm}$ for $20 \mathrm{~min}$ at $4{ }^{\circ} \mathrm{C}$. The $100-\mu$ l supernatant was mixed with $30 \mu \mathrm{l}$ of $5 \times$ Laemmli buffer, and the pellet was resuspended in 100 $\mu \mathrm{l}$ of incubation buffer followed by the addition of $30 \mu \mathrm{l}$ of $5 \times$ Laemmli buffer. After vortexing, $40 \mu \mathrm{l}$ of each fraction was loaded onto a $12 \%$ Tris glycine gel without boiling and separated by SDS-PAGE at $4^{\circ} \mathrm{C}$. After electrophoresis, gels were analyzed in a Storm 860 PhosphorImager (Molecular Dynamics) using blue fluorescence screening for quantitation of the GFP fusion protein band in the gel. Western blot analysis was also performed on parallel samples using the purified polyclonal antibody against GFP (Clontech).

\section{Abbreviations}

GFP: Green fluorescent protein; InsP $\mathrm{P}_{3}$ : Inositol 1,4,5-trisphosphate; PtdIns: Phosphatidylinositol; PtdIns $(4,5) \mathrm{P}_{2}$ : Phosphatidylinositol 4,5-bisphosphate; PLC: Phospholipase C; PM: Plasma membrane.

\section{Authors' contributions}

ZS has created constructs, run most of the experiments, analyzed data, participated in experimental planning, wrote draft of the manuscript, and prepared raw figures. $\mathrm{AB}$ created constructs, prepared recombinant proteins and 
run the InsP $\mathrm{P}_{3}$ and lipid binding assays. YJK has run some of the experiments and analyzed the corresponding data. ML has provided all yeast constructs, discussed data and their implications, read the manuscript. TB has designed experiments, trained ZS to run microscopy experiments, participated in microscopy sessions, analyzed data, completed the writing of the manuscript and prepared the final figures. All authors have seen and approved the final version of the manuscript.

\section{Additional material}

Additional file 1
Figure S1. This is a Figure showing the distribution of some of the GFP-
tagged PH domain constructs
Click here for file
[http://www.biomedcentral.com/content/supplementary/1471-
$2121-10-67-S 1 . E P S]$
Additional file 2
Figure S2. This is a Figure showing the FRAP analysis performed with the
PLC 1 PH and the Tubby domain.
Click here for file
[http://www.biomedcentral.com/content/supplementary/1471-
$2121-10-67-S 2 . D O C]$
Additional file 3
Legend to Fig. S1. This is the legend describing what is shown in Fig. S1
Click here for file
[http://www.biomedcentral.com/content/supplementary/1471-
2121-10-67-S3.EPS]
Additional file 4
Legend to Fig. S2. This is the legend describing what is shown in Fig. S2
Click here for file
[http://www.biomedcentral.com/content/supplementary/1471-
$2121-10-67-S 4 . D O C]$

\section{Acknowledgements}

We are grateful to Dr. Roger $Y$. Tsien for the monomeric red fluorescent protein and to Dr Philip W. Majerus for the human type-IV 5-ptase clone. Confocal imaging was performed at the Microscopy \& Imaging Core of the National Institute of Child Health and Human Development, NIH with the kind assistance of Drs. Vincent Schram and James T. Russell. This research was supported in part by the Intramural Research Program of the Eunice Kennedy Shriver National Institute of Child Health and Human Development of the National Institutes of Health.

\section{References}

I. Berridge MJ: Inositol trisphosphate and diacylglycerol as intracellular messengers. Bio chem J 1984, 220:345-360.

2. Di Paolo G, De Camilli P: Phosphoinositides in cell regulation and membrane dynamics. Nature 2006, 443(7 I I 2):65 I-657.

3. Suh BC, Hille B: Regulation of ion channels by phosphatidylinositol 4,5-bisphosphate. Curr Opin Neurobiol 2005, 15:370-378.

4. Hilgemann DW, Feng S, Nasuhoglu C: The complex and intriguing lives of PIP2 with ion channels and transporters. SCi STKE 200I, 200 I (III):REI9.
5. Kolsch V, Charest PG, Firtel RA: The regulation of cell motility and chemotaxis by phospholipid signaling. J Cell Sci 2008, I 2 I (Pt 5):55 I-559.

6. Raucher D, Stauffer T, Chen W, Shen K, Guo S, York JD, Sheetz MP, Meyer T: Phosphatidylinositol 4,5-bisphosphate functions as a second messenger that regulates cytoskeleton-plasma membrane adhesion. Cell 2000, 100:221-228.

7. Irvine RF: Nuclear inositide signalling -- expansion, structures and clarification. Biochim Biophys Acta 2006, I 76 I (5-6):505-508.

8. Stauffer TP, Ahn S, Meyer T: Receptor-induced transient reduction in plasma membrane Ptdlns(4,5)P2 concentration monitored in living cells. Curr Biol 1998, 8:343-346.

9. Várnai $P$, Balla T: Visualization of phosphoinositides that bind pleckstrin homology domains: calcium-and agonist-induced dynamic changes and relationship to myo- $[3 \mathrm{H}]$ inositollabeled phosphoinositide pools. J Cell Biol 1998, I 43:50 I-5 I0.

10. Varnai P, Balla T: Live cell imaging of phosphoinositide dynamics with fluorescent protein domains. Biochim Biophys Acta 2006, I 76 I (8):957-967.

II. Brown FD, Rozelle AL, Yin HL, Balla T, Donaldson JG: Phosphatidylinositol 4,5-bisphosphate and Arf6-regulated membrane traffic. J Cell Biol 200I, I 54:1007-10I7.

12. Watt SA, Kular G, Fleming IN, Downes CP, Lucocq JM: Subcellular localization of phosphatidylinositol 4,5-bisphosphate using the pleckstrin homology domain of phospholipase $\mathbf{C}$ deltal. Bio chem J 2002, 363:657-666.

13. Hirose K, Kadowaki S, Tanabe M, Takeshima H, lino M: Spatiotemporal dynamics of inositol I,4,5-trisphosphate that underlies complex $\mathrm{Ca2+}$ mobilization patterns. Science 1999, 284: I527-1530.

14. Nash MS, Young KW, Willars GB, Challiss RA, Nahorski SR: Singlecell imaging of graded Ins( $1,4,5) P 3$ production following Gprotein-coupled-receptor activation. Bio chem J 200I, 356(Pt I): $137-142$

15. Lemmon MA: Pleckstrin homology domains: not just for phosphoinositides. Biochem Soc Trans 2004, 32:707-7II.

16. Yu JW, Mendrola JM, Audhya A, Singh S, Keleti D, DeWald DB, Murray $D$, Emr SD, Lemmon MA: Genome-wide analysis of membrane targeting by $S$. cerevisiae pleckstrin homology domains. Mol Cell 2004, I 3:677-688.

17. Carroll K, Gomez C, Shapiro L: Tubby proteins: the plot thickens. Nat Rev Mol Cell Biol 2004, 5:55-63.

18. Santagata S, Boggon TJ, Baird CL, Gomez CA, Zhao J, Shan WS, Myszka DG, Shapiro L: G-protein signaling through tubby proteins. Science 200I, 292:204I-2050.

19. Field SJ, Madson N, Kerr ML, Galbraith KA, Kennedy CE, Tahiliani M, Wilkins A, Cantley LC: Ptdlns(4,5)P2 functions at the cleavage furrow during cytokinesis. Curr Biol 2005, I 5(I 5): | 407-| 4 I2.

20. Nelson CP, Nahorski SR, Challiss RA: Temporal profiling of changes in phosphatidylinositol 4,5-bisphosphate, inositol 1,4,5-trisphosphate and diacylglycerol allows comprehensive analysis of phospholipase C-initiated signalling in single neurons. J Neurochem 2008, I07(3):602-6I5.

21. Quinn KV, Behe P, Tinker A: Monitoring changes in membrane phosphatidylinositol 4,5-bisphosphate in living cells using a domain from the transcription factor tubby. J Physiol 2008, 586(Pt I 2):2855-287I.

22. Balla A, Ju Kim Y, Varnai P, Szentpetery Z, Knight Z, Shokat KM, Balla T: Maintenance of Hormone-sensitive Phosphoinositide Pools in the Plasma Membrane Requires Phosphatidylinositol 4-Kinase III\{alpha\}. Mol Biol Cell 2007, I9(2):71 I-72I.

23. Varnai $P$, Thyagarajan $B$, Rohacs $T$, Balla $T$ : Rapidly inducible changes in phosphatidylinositol 4,5-bisphosphate levels influence multiple regulatory functions of the lipid in intact living cells. J Cell Biol 2006, I 75(3):377-382.

24. Wal J van Der, Habets R, Varnai P, Balla T, Jalink K: Monitoring Phospholipase $\mathbf{C}$ activation kinetics in live cells by FRET. J Biol Chem 200I, 276: I 5337-I5344.

25. Hammond GR, Sim Y, Lagnado L, Irvine RF: Reversible binding and rapid diffusion of proteins in complex with inositol lipids serves to coordinate free movement with spatial information. J Cell Biol 2009, I 84(2):297-308.

26. Balla A, Tuymetova G, Tsiomenko A, Varnai P, Balla T: A plasma membrane pool of phosphatidylinositol 4-phosphate is generated by phosphatidylinositol 4-kinase type-III alpha: stud- 
ies with the $\mathrm{PH}$ domains of the oxysterol binding protein and FAPPI. Mol Biol Cell 2005, 16:1282-1295.

27. Varnai P, Lin X, Lee SB, Tuymetova G, Bondeva T, Spat A, Rhee SG, Hajnoczky G, Balla T: Inositol lipid binding and membrane localization of isolated pleckstrin homology (PH) domains. Studies on the PH domains of phospholipase C delta I and pl30. J Biol Chem 2002, 277:274I 2-27422.

28. Uchiyama T, Yoshikawa F, Hishida A, Furuichi T, Mikoshiba K: A novel recombinant hyper-affinity Inositol I,4,5-trisphosphate (IP3) absorbent traps IP3, resulting in specific inhibition of IP3-mediated calcium signaling. J Biol Chem 200I, 277:8106-8II3.

29. Varnai P, Balla A, Hunyady L, Balla T: Targeted expression of the inositol I,4,5-triphosphate receptor (IP3R) ligand-binding domain releases $\mathrm{Ca2}+$ via endogenous IP3R channels. Proc Natl Acad Sci USA 2005, I 02(22):7859-7864.

30. Xu C, Watras J, Loew LM: Kinetic analysis of receptor-activated phosphoinositide turnover. / Cell Biol 2003, 161:779-79I.

31. Bartlett PJ, Young KW, Nahorski SR, Challiss RA: Single cell analysis and temporal profiling of agonist-mediated inositol I,4,5trisphosphate, $\mathbf{C a 2 +}$, diacylglycerol, and protein kinase $\mathbf{C}$ signaling using fluorescent biosensors. J Biol Chem 2005, 280(23):21837-21846.

32. Roy A, Levine TP: Multiple pools of phosphatidylinositol 4phosphate detected using the pleckstrin homology domain of Osh2p. J Biol Chem 2004, 279:44683-44689.

33. Yeung T, Terebiznik M, Yu L, Silvius J, Abidi WM, Philips M, Levine T, Kapus A, Grinstein S: Receptor activation alters inner surface potential during phagocytosis. Science 2006, 3 I3(5785):347-35I.

34. Shi X, Basran J, Seward HE, Childs W, Bagshaw CR, Boxer SG: Anomalous negative fluorescence anisotropy in yellow fluorescent protein (YFP 10C): quantitative analysis of FRET in YFP dimers. Biochemistry 2007, 46(50): | 4403-| $44 \mid 7$.

35. Nash MS, Willets JM, Billups B, John Challiss RA, Nahorski SR: Synaptic activity augments muscarinic acetylcholine receptorstimulated inositol I,4,5-trisphosphate production to facilitate $\mathrm{Ca2}+$ release in hippocampal neurons. J Biol Chem 2004, 279(47):49036-49044.

36. Nash MS, Schell MJ, Atkinson PJ, Johnston NR, Nahorski SR, Challiss RA: Determinants of metabotropic glutamate receptor-5mediated $\mathrm{Ca} 2+$ and inositol 1,4,5-trisphosphate oscillation frequency. Receptor density versus agonist concentration. J Biol Chem 2002, 277(39):35947-35960.

37. Watras J. Fink CC, Loew LM: Endogenous inhibitors of InsP3. induced Ca2+ release in neuroblastoma cells. Brain Res 2005, I 055( I-2):60-72.

38. Horowitz LF, Hirdes W, Suh BC, Hilgemann DW, Mackie K, Hille B Phospholipase $C$ in living cells: activation, inhibition, $\mathrm{Ca2+}$ requirement, and regulation of M current. J Gen Physiol 2005, I 26(3):243-262.
Publish with Bio Med Central and every scientist can read your work free of charge

"BioMed Central will be the most significant development for disseminating the results of biomedical research in our lifetime. "

Sir Paul Nurse, Cancer Research UK

Your research papers will be:

- available free of charge to the entire biomedical community

- peer reviewed and published immediately upon acceptance

- cited in PubMed and archived on PubMed Central

- yours - you keep the copyright
BioMedcentral 